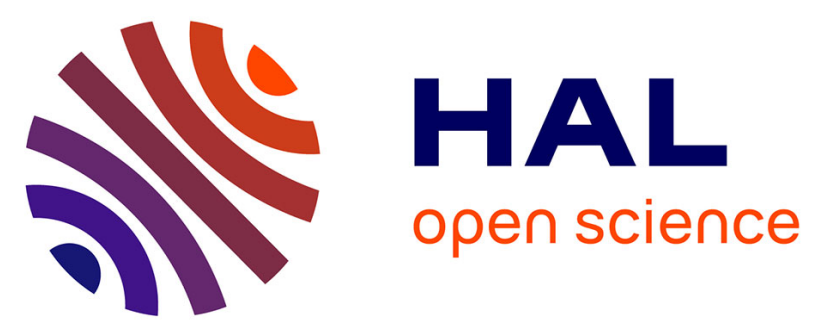

\title{
Competition within low-density bacterial populations as an unexpected factor regulating carbon decomposition in bulk soil
}

\author{
Alexandre Coche, Tristan Babey, Alain Rapaport, Laure Vieublé Gonod, \\ Patricia Garnier, Naoise Nunan, Jean-Raynald de Dreuzy
}

\section{To cite this version:}

Alexandre Coche, Tristan Babey, Alain Rapaport, Laure Vieublé Gonod, Patricia Garnier, et al.. Competition within low-density bacterial populations as an unexpected factor regulating carbon decomposition in bulk soil. Soil Biology and Biochemistry, 2022, 164 (108423), 10.1016/j.soilbio.2021.108423 . insu-03347522v3

\section{HAL Id: insu-03347522}

https://hal-insu.archives-ouvertes.fr/insu-03347522v3

Submitted on 23 Nov 2021

HAL is a multi-disciplinary open access archive for the deposit and dissemination of scientific research documents, whether they are published or not. The documents may come from teaching and research institutions in France or abroad, or from public or private research centers.
L'archive ouverte pluridisciplinaire HAL, est destinée au dépôt et à la diffusion de documents scientifiques de niveau recherche, publiés ou non, émanant des établissements d'enseignement et de recherche français ou étrangers, des laboratoires publics ou privés. 
1 Competition within low-density bacterial populations as an

2 unexpected factor regulating carbon decomposition in bulk soil

3 Alexandre Coche $^{\mathrm{a}^{*}}$, Tristan Babey ${ }^{\mathrm{b}}$, Alain Rapaport ${ }^{\mathrm{c}}$, Laure Vieublé Gonod ${ }^{\mathrm{d}}$,

4 Patricia Garnier ${ }^{d}$, Naoise Nunan ${ }^{\text {eff }}$, Jean-Raynald de Dreuzy ${ }^{\mathrm{a}}$

5 a Univ Rennes, CNRS, Géosciences Rennes - UMR 6118, F-35000 Rennes, France

6 b Stanford University, Department of Earth System Science, Stanford, USA

7 ' MISTEA, Univ. Montpellier, INRAE, Montpellier SupAgro, France

8 d UMR Ecosys, INRAE, AgroParisTech, Université Paris-Saclay, 78850, Thiverval Grignon,

9 France

e Sorbonne Université, CNRS, IRD, INRAE, P7, UPEC, Institute of Ecology and Environmental

11 Sciences-Paris, 4 place Jussieu, 75005 Paris, France

$12{ }^{\mathrm{f}}$ Department of Soil \& Environment, Swedish University of Agricultural Sciences, P.O. Box

137014,75007 Uppsala, Sweden

$14{ }^{*}$ Corresponding author. E-mail address: alexandre.coche@univ-rennes1.fr (A. Coche)

15 Abstract

16 Bacterial decomposition of organic matter in soils is generally believed to be mainly

17 controlled by the access bacteria have to organic substrate. The influence of bacterial traits

18 on this control has, however, received little attention. Using the substrate-dependent

19 Monod growth model, we develop a bioreactive transport model to screen the interactive

20 impacts of spatial dispersion and bacterial traits on mineralization. Bacterial traits primarily 
21 involved in the bacterial response to the substrate concentration, such as the maximum

22 specific uptake rate and efficiency, the adaptation time of the uptake rate and the initial

23 population density, are considered. We compare the model results with two sets of

24 previously performed $\mathrm{cm}$-scale soil-core experiments in which the mineralization of the

25 pesticide 2,4-D was measured under well-controlled initial distributions and transport

26 conditions. Bacterial dispersion away from the initial substrate location induced a significant

27 increase in 2,4-D mineralization. It reveals an increase of specific uptake rates at lower bacterial densities, more than compensating the decrease of specific uptake rates caused by substrate dilution. This regulation of bacterial activities by density, caused by the local depletion of substrate by competing bacteria, becomes dominant for bacteria with an efficient uptake of substrate at low substrate concentrations (a common feature of oligotrophs). Such oligotrophs, commonly found in soils, compete with each other for substrate even at remarkably low population densities. The ratio-dependent Contois growth model, which includes a density regulation in the expression of the uptake efficiency, is more accurate and convenient to calibrate than the substrate-dependent Monod model, at least under these conditions. In view of their strong interactions, bioreactive and transport processes cannot be handled independently but should be integrated, in particular when reactive processes of interest are carried out by oligotrophs.

39 Keywords: biodegradation of organic matter; heterogeneous spatial distributions; bioreactive transport model; competition for substrate; bacterial traits; ratio-dependent 41 growth 


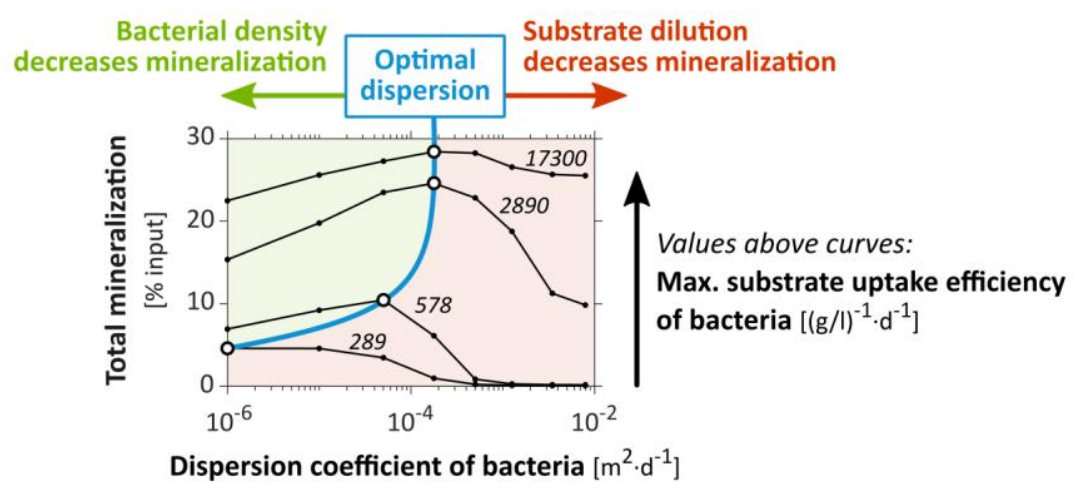

42

\section{Highlights}

$44 \quad$ - The impact of spatial distributions on decomposition depends on bacterial traits

45 - Decomposition can be reduced by competition between bacteria even at low densities

46 - Bacterial density regulation counterbalances substrate accessibility regulation

47 - Regulation of decomposition by bacterial density is more acute for oligotrophs

\section{Introduction}

Organic carbon is involved in most ecological functions provided by soils (Bünemann et al., 2018). Its cycling in soil depends upon the activity of microorganisms. Soluble organic molecules are taken up as substrates by specific populations of soil bacteria, and degraded

52 inside the cells by endoenzymes to provide carbon and energy. This is precisely the case for

53 the 2,4-Dichlorophenoxyacetic acid (2,4-D) used in this study as a generic model compound

54 (Don and Weightman, 1985; Pieper et al., 1988; Boivin et al., 2005). Bacterial degradation of 55 soil carbon has generally been modeled with the Monod equation, where the specific 56 substrate uptake rate is controlled by substrate concentration and bacterial traits such as 57 the maximum specific growth rate, the yield (or carbon use efficiency) and the "maximum 
specific uptake efficiency" (e.g. Monod, 1949; Sinton et al., 1986; Cheyns et al., 2010). With the Monod equation, at the lowest substrate concentration, the specific uptake rate is linearly proportional to the substrate concentration. The proportionality factor is referred to here as the "maximum uptake efficiency" and it reflects the maximal ability of the cell to capture substrate molecules that collide with its membrane (Button, 1978, 1983). The maximum uptake efficiency can also be understood as the volume from which a cell can harvest substrate per unit of time, as used in some studies (Desmond-Le Quéméner and Bouchez, 2014; Nunan et al., 2020; Ugalde-Salas et al., 2020). Each bacterium is assumed to be exposed to the whole substrate concentration of its surroundings, without any limitation by the population density (Lobry and Harmand, 2006).

The direct contact (exposure) between bacteria and substrate depends on their spatial distributions (Holden and Firestone, 1997; Nunan et al., 2007). Bacteria and substrate are both heterogeneously distributed as a result of numerous biotic and abiotic processes (Dechesne et al., 2014; Kuzyakov and Blagodatskaya, 2015). There are complex feedback loops between these distributions, dispersive transport processes such as diffusion and hydrodynamic dispersion (Madsen and Alexander, 1982; Breitenbeck et al., 1988), and the bacterial activity itself such as consumption and growth (Poll et al., 2006).

Aggregated bacterial distributions, as observed at the mm-scale for 2,4-D degraders (Vieublé Gonod et al., 2003), have been shown to decrease degradation rates when the distribution of substrate is homogeneous, because of local substrate depletion (Pallud et al., 2004; Dechesne et al., 2010). Yet, the role of bacterial metabolic traits on the impact of bacterial and substrate distributions on degradation remains mostly unknown, especially when substrate and bacteria are heterogeneously and dynamically redistributed in soils over 
$81 \mu \mathrm{m}$-to-cm scales by numerous spatial disturbances (Madsen and Alexander, 1982;

82 Breitenbeck et al., 1988; König et al., 2020). We investigated the extent to which bacterial

83 activity and transport processes can be treated independently or should be integrated to 84 characterize, understand and predict degradation under various advective, diffusive and 85 dispersive conditions. The simultaneous characterization of the impacts of bacterial traits and transport parameters through their mutual interactions is methodologically challenging.

It requires several well-controlled experiments in comparable degradation conditions, with specific spatial distributions of substrate and degraders in specific transport conditions, and a spatiotemporal monitoring of the different carbon pools.

Among the scarce relevant datasets (e.g. Dechesne et al., 2010), we used the two sets of $\mathrm{cm}$-scale soil-core experiments performed by Pinheiro et al. $(2015,2018)$, in which the degradation of 2,4-D under different initial spatial distributions and transport conditions was measured in similar repacked soil columns. Mostly reported independently, they have shown first that the proximity between bacteria and the initial location of a heterogeneously distributed substrate exerts a strong control on mineralization. Mineralization was greater when bacteria were close to the initial location of substrate, even though most of the initial dissolved substrate diffused away from its initial location. This was attributed to the fact that bacteria located far from the initial substrate location were only exposed to highly diluted substrate concentrations (Babey et al., 2017). However, the hydrodynamic dispersion of both bacteria and substrate away from their initial location caused a greater than four-fold increase in the mineralization of substrate that was not leached out, to the point that it almost reached the same performance as in homogeneous conditions in which there was no dilution (Pinheiro et al., 2018). The surprising increase in mineralization suggests a regulation 
of mineralization by population density compensating the effect of substrate dilution, the activity of bacteria being enhanced when their density is diluted by the dispersive

106 percolation events. While such regulations by bacterial density have not yet been considered 107 in soils, presumably because of the extremely low apparent bacterial densities found in soils 108 (Young et al., 2008), they are well known in bioreactors, where they are usually modeled by 109 the ratio-dependent Contois growth law (Contois, 1959; Harmand and Godon, 2007).

110 In order to determine the relevance of the putative bacterial decomposer density effect on

111 decomposition, we developed a quantitative approach to model the two sets of experiments

112 within the same unified framework (section 2). We assessed the relevance of previously 113 developed models, improved the calibration of a Monod-based model and investigated an 114 alternative Contois-based model (section 3). We discuss the implication of the results on the 115 controlling factors of soil organic carbon cycling, on the relevant bacterial growth models 116 and on the possible bacterial strategies (section 4).

\section{2. Models and methods}

\section{2.1. Experiment scheme, geometry and initial distributions}

119 We briefly introduce the experiments performed previously and highlight aspects of the 120 experiments that are important for the modeling (Fig. 1). The full experimental setting is 121 presented in the supplementary materials (Fig. S1 and Table S1) for the sake of 122 completeness. Soil columns were packed with two homogeneous or heterogeneous 123 arrangements of soil cubes, either sterilized, or hosting the indigenous microbial 124 communities (referred to as "degraders") and amended with ${ }^{14} \mathrm{C}$-labelled 2,4-D (referred to 
125 as "substrate"). Two sets of experiments, referred to as "hydrostatic" and "percolation"

126 conditions, were performed respectively with only substrate diffusion (Pinheiro et al., 2015),

127 or with additional substrate and bacterial advection and dispersion caused by water

128 percolation (Pinheiro et al., 2018). The initial locations of the bacteria and substrate were

129 set in the model according to the experimental conditions (Fig 1A). Initial concentrations

130 used in the model are detailed in Table 1. In the experiments, the mass of mineralized ${ }^{14} \mathrm{C}$

131 derived from the degradation of the labelled 2,4-D was monitored at the core scale during

132 at least two weeks (Fig. 1B). These data were used to confront the model processes with a

133 physical system, as detailed in section 2.5 . 

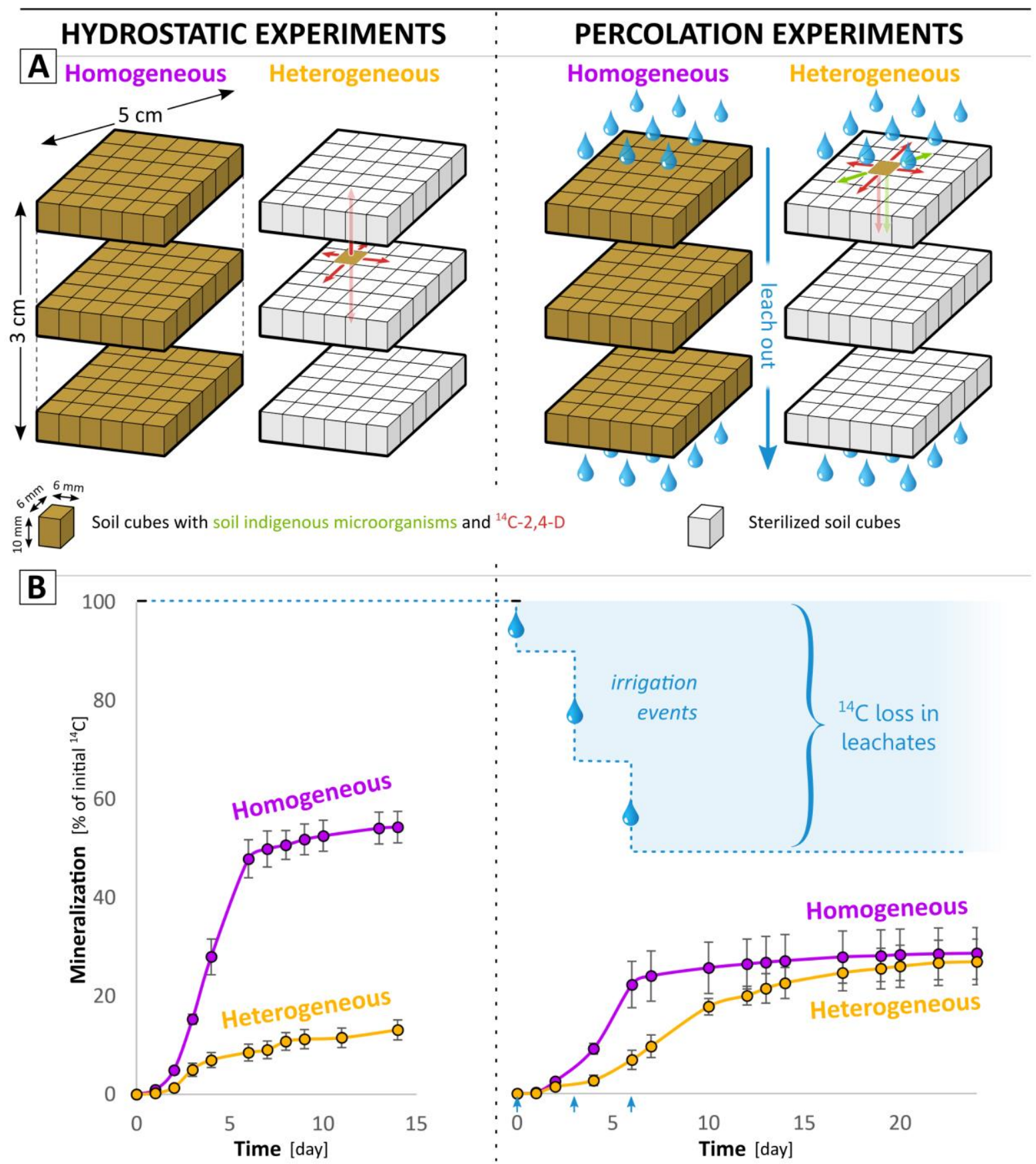

135 Fig. 1. Model experimental design, geometry and initial distributions (A) based on previously 136 performed experiments in hydrostatic (Pinheiro et al., 2015) and percolation (Pinheiro et al., 137 2018) conditions. The red and green arrows refer respectively to the 2,4-D and degrader 138 modeled displacements. (B) Experimental cumulated production of $\mathrm{CO}_{2}$ (adapted from 139 Pinheiro et al. $(2015,2018)$, permission for reproduction granted by Elsevier). 


\subsection{Bioreactive model}

141 The bioreactive model extends the model published by Babey et al. (2017) (Fig. 2) to account

142 for Contois growth law as an alternative to Monod's. The sorption processes, the bacterial

143 lag phase and the biomass recycling described below were previously discussed and their

144 use justified in Babey et al. (2017) to consistently represent the experimental data. The $r(\cdot)$

145 notation expresses the reaction rates of the biochemical dynamics that are expressed as

146 follows:

$$
\begin{aligned}
& r(S)=k_{A S} A-k_{S A} S-k_{R} S-\frac{\mu}{y} B+m_{t} \chi B \\
& r(A)=k_{S A} S-k_{A S} A \\
& r\left(R_{S}\right)=k_{R} S \\
& r\left(C O_{2}\right)=\frac{(1-y)}{y} \mu B \\
& r(B)=\mu B-m_{t} B \\
& r\left(R_{B}\right)=m_{t}(1-\chi) B
\end{aligned}
$$

147 All variable and parameter definitions are listed in Table 1. The dynamics of the specific

148 growth rate $\mu$ are given, for the Monod-based model, by:

$$
\frac{\partial \mu}{\partial t}=\alpha\left(\mu_{\max } \frac{S}{\kappa_{M}+S}-\mu\right)
$$

149 and, for the Contois-based model, by:

$$
\frac{\partial \mu}{\partial t}=\alpha\left(\mu_{\max } \frac{S / B}{\kappa_{C}+S / B}-\mu\right)=\alpha\left(\mu_{\max } \frac{S}{\kappa_{C} B+S}-\mu\right)
$$

150 where $\mu=0$ at $t=0$. 


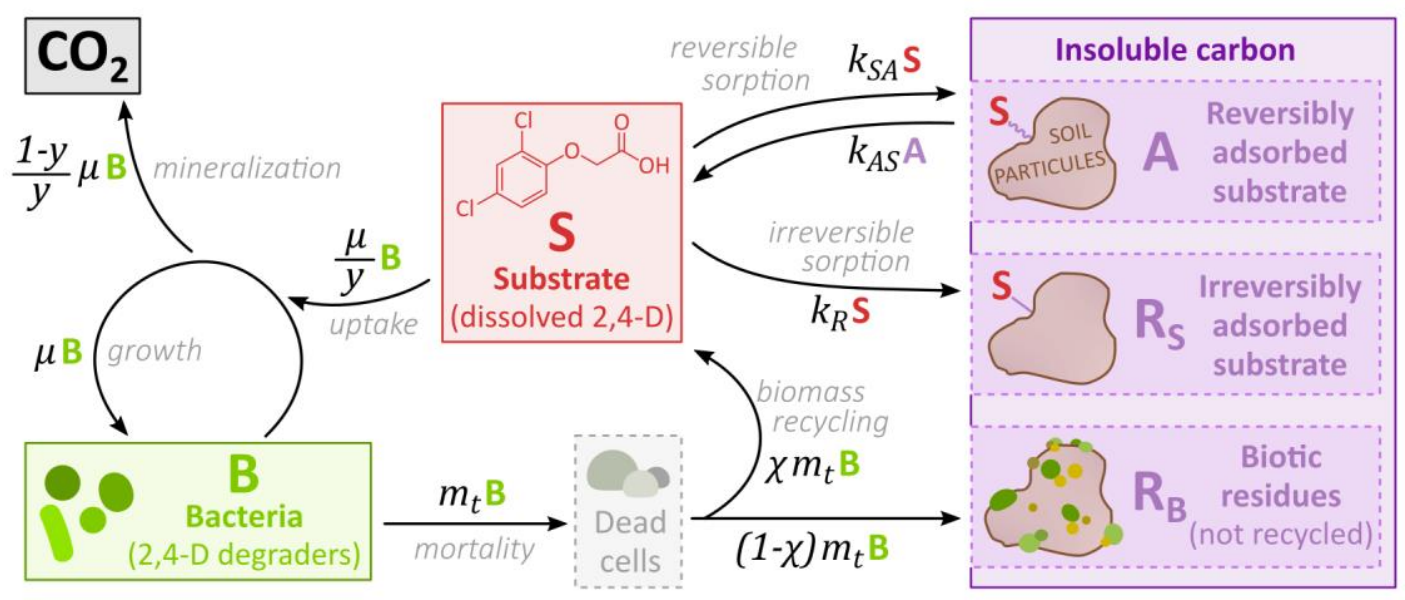

152 Fig. 2. Graphical representation of the biochemical model and carbon fluxes identified by the

153 arrows. Under low substrate concentrations $S$, the specific uptake rate $(1 / y) \cdot \mu$ becomes 154 equal to $S \cdot(1 / y) \cdot \mu_{\max } / \kappa_{M}$, where $(1 / y) \cdot \mu_{\max } / \kappa_{M}$ is referred to as the "maximum specific 155 uptake efficiency".

\section{Table 1.}

157 Values and range of values of the reactive transport model. The effective dispersion 158 coefficient $d_{d i s p}$ applies only to heterogeneous percolation experiments. $B(t=0)$ is the initial 159 density of bacteria in the natural cubes. It is considered 1.6 times smaller in the percolation experiments than in the hydrostatic experiments according to the initial experimental 161 measurements.

$\begin{array}{lll}\text { Parameter description Symbol Unit } & \begin{array}{l}\text { Fixed values and } \\ \text { admissible ranges } \\ \text { for screening }\end{array}\end{array}$

\begin{tabular}{|c|c|c|c|c|}
\hline \multirow{2}{*}{$\begin{array}{l}\text { Initial } \\
\text { substrate } \\
\text { concentrati } \\
\text { on }\end{array}$} & $\begin{array}{l}\text { Hydrostatic } \\
\text { experiments }\end{array}$ & $S(t=0)$ & $\begin{array}{l}\mu \mathrm{g} \cdot \mathrm{g}^{-1} \text { (mass of substrate } \\
\text { carbon per mass of dry soil) }\end{array}$ & $0.825^{b}$ \\
\hline & $\begin{array}{l}\text { Percolation } \\
\text { experiments }\end{array}$ & & $\mu g \cdot g^{-1}$ & $6.52^{b}$ \\
\hline
\end{tabular}

Reversible adsorption coefficient

Reversible desorption coefficient

$\boldsymbol{k}_{A S}$

$d^{-1}$

Irreversible adsorption coefficient

kc

$d^{-1}$

0.01296 
Uptake yield

Maximum specific

uptake rate

$(1 / y) \cdot \mu_{\max } \quad d^{-1}$

[0.0190-19.5]

Specific uptake efficiency at the lowest substrate

$(1 / y) \cdot \mu_{\max } / \kappa^{a}$

$\mathrm{g} \cdot \mu \mathrm{g}^{-1} \cdot \mathrm{d}^{-1}$ (mass of dry soil per

where $\kappa$ is $\kappa_{M}$ or

concentration

$B(t=0) \cdot \kappa C$

mass of bacterial carbon per unit of time)

$[0.0152-159]^{c}$

Accommodation

rate

$\alpha \quad \mathrm{d}^{-1}$

[0.00934-934]

\begin{tabular}{|c|c|c|c|c|}
\hline \multirow{2}{*}{$\begin{array}{l}\text { Initial } \\
\text { degrader } \\
\text { population } \\
\text { density }\end{array}$} & $\begin{array}{l}\text { Hydrostatic } \\
\text { experiments }\end{array}$ & $B(t=0)$ & $\begin{array}{l}\mu \mathrm{g} \cdot \mathrm{g}^{-1} \text { (mass of } \\
\text { bacterial carbon per mass of } \\
\text { dry soil) }\end{array}$ & {$[0.0161-1.61]^{d}$} \\
\hline & $\begin{array}{l}\text { Percolation } \\
\text { experiments }\end{array}$ & $B(t=0)$ & $\mu g \cdot g^{-1}$ & {$[0.0101-1.01]^{d}$} \\
\hline \multicolumn{2}{|c|}{ Mortality rate } & $\boldsymbol{m}_{t}$ & $d^{-1}$ & 0.0602 \\
\hline \multicolumn{2}{|c|}{ Biomass recycling yield } & $\chi$ & - & 0.6010 \\
\hline \multicolumn{2}{|c|}{$\begin{array}{l}\text { Effective diffusion } \\
\text { coefficient }\end{array}$} & $\boldsymbol{d}_{\text {diff }}$ & $m^{2} \cdot d^{-1}$ & $110^{-5} e$ \\
\hline \multicolumn{2}{|c|}{$\begin{array}{l}\text { Effective dispersion } \\
\text { coefficient }\end{array}$} & $d_{d i s p}$ & $m^{2} \cdot d^{-1}$ & {$[0-\infty]$} \\
\hline $\begin{array}{l}\text { Leaching } \\
\text { rates } \\
\text { (days 0; 3; } \\
\text { 6) }\end{array}$ & $\begin{array}{l}\text { Homogeneous } \\
\text { experiments } \\
\text { Heterogeneous } \\
\text { experiments }\end{array}$ & $\boldsymbol{v}$ & - & $0.107 ; 0.223 ; 0.178$ \\
\hline
\end{tabular}

$a$ The half-saturation constant $\kappa$ corresponds to $\kappa_{M}$ for the Monod-based model and

$163 B(t=0) \cdot \kappa_{C}$ for the Contois-based model (where $B(t=0)$ is the value from the hydrostatic 164 experiments).

$165 b^{b}$ The initial substrate concentration $S(t=0)$ is set equal to the ${ }^{14} C-2,4-D$ concentration 166 amended in the experiments.

$167{ }^{c}$ The values of $(1 / y) \cdot \mu_{\max } / \kappa$ correspond to ranges of $\left[1.65-1.7310^{4}\right] \mathrm{l} \cdot \mathrm{g}^{-1} \cdot \mathrm{d}^{-1}$ (volume of 168 water per mass of bacteria per unit of time)

$169{ }^{d}$ The values of $B(t=0)$ correspond respectively to ranges of $\left[1.4810^{-4}-1.4810^{-2}\right] \mathrm{g} \cdot \mathrm{l}^{-1}($ mass

170 of bacteria per volume of water) for the hydrostatic experiments and [9.24 $10^{-5}-9.24$

$\left.171 \quad 10^{-3}\right] \mathrm{g} \cdot \mathrm{l}^{-1}$ for the percolation experiments.

$172{ }^{e}$ The value of $d_{\text {diff }}$ has been calibrated on a $3 \times 6 \times 6$ grid in similar conditions (Babey et al., 173 2017). 
174 The dissolved substrate $S$ is either reversibly adsorbed to soil particles (pool $A$ ) or irreversibly

175 adsorbed (pool $R_{S}$ ) (Eqs. (1), (2), (3)), or taken up by bacteria $B$ (Eq. (1)) and metabolized into

$176 \mathrm{CO}_{2}$ (Eq. (4)) and new biomass $B$ (Eq. (5)). $k S A$ and $k_{A S}$ are the reversible sorption coefficients.

$177 k_{R}$ is the irreversible one. Bacteria death occurs at a constant rate $m_{t}$ (Eq. (5)) and a fraction

178 of the bacterial necromass is considered to return to the dissolved substrate pool $S$ to

179 account for biomass recycling (Eq. (1)), while the rest is transformed to biotic residues $R_{B}$

180 (Eq. (6)). The remobilization of carbon previously absorbed by bacteria is necessary to

181 adequately predict the slower dynamics of mineralization that takes place once most of the

182 dissolved substrate has been consumed, observed after 5 days in homogeneous experiments

183 and after respectively 3 or 10 days in the heterogeneous hydrostatic or percolation

184 experiments. This remobilization is modeled in the form of a biomass recycling in order to

185 be consistent with the model previously published in Babey et al. (2017), but similar effects

186 could be achieved by other mechanisms, like a slower mineralization of biogenic residues

187 (Fig. S9). Its impact on the final mineralization does not account for more than $10 \%$ of the

188 substrate that is not leached out. The adsorbed substrate and biotic residues form the pool

189 of insoluble carbon $A+R_{S}+R_{B}$. The substrate $S$ is consumed by bacteria $B$ according to their

190 specific uptake rate $(1 / y) \cdot \mu$ expressed either by the substrate-dependent Monod growth law

191 (Eq. (7)) (Monod, 1949) or by the ratio-dependent Contois growth law (Eq. (8)) (Contois,

192 1959). The yield coefficient $y$ relates the specific uptake rate $(1 / y) \cdot \mu$ to the specific growth

193 rate $\mu . \mu_{\max }$ is the maximum specific growth rate. $\kappa_{M}$ and $\kappa_{C}$ are Monod and Contois constants

194 respectively. The effective uptake is delayed by the accommodation rate $\alpha$, which explicitly

195 takes into account the "memory" effects of the bacteria when adapting to new conditions

196 (Patarinska et al., 2000). This delay is necessary to capture the mineralization lag time at the

197 beginning of the experiments (see Fig. S10). Over long time periods $(t \gg 1 / \alpha), \mu$ follows the 
198

exact expression of the Monod or Contois equations. All modeled pools $\left(S, B, C O_{2}, A, R_{S}\right.$ and $R_{B}$ ) were expressed as carbon concentrations in $\mu \mathrm{g} \cdot \mathrm{g}^{-1}$ (mass of carbon per mass of dry soil) considering a soil water content of $0.205 \mathrm{~g} \cdot \mathrm{g}^{-1}$ (mass of water per mass of dry soil), a bulk density of the soil column of $1.310^{3} \mathrm{~g} \cdot \mathrm{l}^{-1}$ (mass of dry soil per apparent soil volume) and an average bacterial dry weight of $2.810^{-13} \mathrm{~g}$ corresponding to $1.4910^{-13} \mathrm{~g}$ of carbon per cell. These values of water content and bulk density were those set up in the experiments, the latter corresponding to a water potential adjusted at $-31.6 \mathrm{kPa}(\mathrm{pF} 2.5)$. The average bacterial weight was assumed based on Dechesne et al. (2010) and Pinheiro et al. (2015). The waterfilled pore space (54\%, volume of water per volume of pores) was such that oxygen was not considered a limiting factor for 2,4-D degradation.

\subsection{Reactive transport model}

The transport model is based on the substrate diffusion model of Babey et al. (2017) to which advective-dispersive processes explored in the experiments of Pinheiro et al. (2018) are added. Hydrodynamic leaching out and dispersion of bacteria and substrate were observed in the percolation experiments while the substrate was reported to diffuse in all experiments. Hydrodynamic leaching and dispersion were modeled independently, as they result from, respectively, bypass flow through large pores and complex hydrodynamic dispersion processes coming not only from usual flow mechanisms but also from large saturation variations and local redistribution of moisture in the pore network. Due to the lack of adequate experimental data to characterize the details of the dispersion process, we applied a simple isotropic dispersion coefficient. Complementary numerical simulations show that other anisotropic dispersion parameterizations are only weakly sensitive (Fig. S3 
220 and S4). Bacterial and substrate transports by percolation were described with the same

221 advective and dispersive parameters. This assumption did not significantly alter the results

222 (Fig. S5 and S6). Coupled to the equations of the bioreactive model ((1)-(8)), the full reactive

223 transport model is given by:

$$
\begin{aligned}
& \frac{\partial S}{\partial t}=r(S)+\nabla\left(d_{\text {diff }} \nabla S\right)+G\left(\nabla\left(d_{\text {disp }} \nabla S\right)-v S\right) \\
& \frac{\partial B}{\partial t}=r(B)+G\left(\nabla\left(d_{\text {disp }} \nabla B\right)-v B\right) \\
& \frac{\partial U}{\partial t}=r(U) \quad \text { for } U=A, R_{B}, R_{S} \text { and } \mathrm{CO}_{2}
\end{aligned}
$$

224 where $d_{\text {diff }}$ is the effective molecular diffusion coefficient of $S, d_{\text {disp }}$ is the effective 225 hydrodynamic dispersion coefficient of $S$ and $B$ and $v$ is their leaching rate. Note that the 226 dispersion coefficient $d_{\text {disp }}$ mostly affected the spreading of bacteria, given that substrate 227 was mainly spread by diffusion, as confirmed by consistent results from equivalent models 228 without hydrodynamic dispersion of $S$ (Fig. S7 and S8). Effective diffusion and dispersion 229 processes were assumed to be isotropic and uniform at the column-scale. Dispersion and 230 leaching were active only during the observed 1-hour percolation events at days 0, 3 and 6 231 as controlled by the function $G$ defined as:

$$
\begin{aligned}
& G(t)=1 \text { for } t=[0 \mathrm{~d}-0 \mathrm{~d} 1 \mathrm{~h}] ;[3 \mathrm{~d}-3 \mathrm{~d} 1 \mathrm{~h}] ;[6 \mathrm{~d}-6 \mathrm{~d} 1 \mathrm{~h}] \\
& G(t)=0 \text { otherwise. }
\end{aligned}
$$

232 No-flow boundary conditions were imposed at the edges of the soil core $(\nabla S=0$ and $\nabla B=0)$

233 during periods outside of the percolation events. The transient evolutions of the water 234 content and their effects on concentrations were not considered because of the short 
235 duration of the percolation events $(1 \mathrm{~h})$ and the absence of detectable effects on the 236 experimental mineralization curve around the percolation events (Fig. 1D). Hydration 237 conditions were considered constant, constrained by the water potential adjusted 238 to $-31.6 \mathrm{kPa}$. No bacterial mobility was observed in the hydrostatic experiments, suggesting 239 that the bacterial mobility observed in the percolation experiments resulted primarily from 240 hydrodynamic dispersion.

241 Carbon pools concentration dynamics were simulated on a $3 \times 6 \times 6$ regular mesh grid. 242 Although the shape of the grid was slightly different from that of the cylindrical soil-core, it 243 did not have any observable impact (Babey et al., 2017). We recall that substrate and 244 bacteria were initially co-located in the same cube(s). Each cube was considered to be 245 physically, chemically and biologically homogeneous. Diffusion and dispersion were 246 simulated using a finite-difference scheme (Iserles, 2009) and coupled with the bioreactive 247 model, itself solved by the $4^{\text {th }}$ order Runge-Kutta integration method function of MATLAB 248 (Shampine and Reichelt, 1997). The coupling of transport and bioreactive models was 249 achieved with a sequential non-iterative operator-splitting method, in which the equations 250 are resolved within each time step in a sequence of one transport step followed by one 251 bioreactive step (Carrayrou et al., 2004; Lagneau and van der Lee, 2010). The time steps were 252 smaller than the characteristic diffusion and reaction times to avoid any coupling issues.

\section{2.4. Exploratory screening}

254 Parameters and their values are listed in Table 1. Sorption parameters and the diffusion 255 coefficient were set at values that were calibrated and validated by Babey et al. (2017) in 256 independent experiments without degradation. The mortality rate and the biomass recycling 
yield were also kept at the values calibrated in Babey et al. (2017) as they were considered

258 to be well constrained by the residual mineralization dynamics of the homogeneous

259 hydrostatic experiment (Fig. 1D). The four biological parameters primarily involved in the

260 biological response of bacteria to the concentration of substrate were determined to be

$261(1 / y) \cdot \mu_{\max }, \alpha, B(t=0)$ and either $(1 / y) \cdot \mu_{\max } / \kappa_{M}$ for the Monod-based model or

$262(1 / y) \cdot \mu_{\max } /\left(B(t=0) \cdot \kappa_{c}\right)$ for the Contois-based model. Each of these four parameters were

263 sampled over 7 logarithmically-distributed values within the theoretically and physically

264 relevant ranges given by Babey et al. (2017), and all possible combinations of values were

265 screened (Table S2). We recall that the maximum specific uptake efficiency $(1 / y) \cdot \mu_{\max } / \kappa_{M}$

266 characterizes the bacterial uptake of substrate at the lowest substrate concentration

267 (Button, 1991), while the maximum specific uptake rate $(1 / y) \cdot \mu_{\max }$ characterizes the

268 bacterial uptake at the highest substrate concentration. Note that the uptake yield $y$ was

269 fixed at the value calibrated by Babey et al. (2017) with a high degree of certainty. The initial

270 maximum uptake efficiency $(1 / y) \cdot \mu_{\max } /(B(t=0) \cdot \kappa c)$ in the Contois-based model was

271 screened in the same range as $(1 / y) \cdot \mu_{\max } / \kappa_{M}$. The accommodation rate $\alpha$ of the degrader

272 response ranged from a negligible delay of few minutes $\left(\alpha=934 \mathrm{~d}^{-1}\right)$ to a prolonged delay of

273 around 10 days $\left(\alpha=9.3410^{-2} \mathrm{~d}^{-1}\right) . B(t=0)$ values were screened around the initial

274 experimental measurements of the $t f d A$ gene copy number, assuming that one $t f d A$

275 sequence corresponded to one bacterium. They ranged over two orders of magnitude to

276 account for the uncertainty of the conversion of $t f d A$ copy number into alive 2,4-D degraders

277 (Bælum et al., 2006, 2008). Bacterial density in the uptake efficiency expression will also be

278 expressed in $\mathrm{g} \cdot \mathrm{l}^{-1}$ (mass of bacteria per volume of water) for a more direct comparison with

279 the relevant literature. 
The spatial distribution of bacteria observed at the end of the experiments could not be used

281 to determine the effective dispersion coefficient $d_{d i s p}$ (Fig. S2). While they qualitatively

282 ascertained that bacteria spread orthogonally to the percolation direction, experimental

283 data were not sufficiently resolved to be used quantitatively. The dispersion coefficient was

284 thus screened over 10 values ranging from no dispersion ( $\left.d_{\text {disp }}=0\right)$ to complete instant

285 homogenization of the soil core $\left(d_{d i s p}=\mathrm{inf}\right)($ Table S2). In order to analyze the result of

286 bacterial dispersion in terms of distance from the initial location of the substrate, we

287 compute the root-mean-square displacement of bacteria, defined as the root-mean-square

288 of their spreading during the duration $\Delta t$ of one percolation event and expressed as

$289 \sqrt{6 d_{\text {disp }} \Delta t}$ (Stana, 2020). The effective diffusion coefficient $d_{\text {diff }}$ had been calibrated

290 independently from percolation conditions (Pinheiro et al., 2015; Babey et al., 2017). The

291 leaching rates $v$ were determined based on the experimental masses of leached ${ }^{14} \mathrm{C}$ (Pinheiro

292 et al., 2018) (Table 1). Detailed values for the screened parameters are listed in Table S2.

\section{2.5. Model to data comparison}

294 The comparison between the results of the model and the experimental data was based on

295 the core-scale data of mineralization deduced from the carbon mass $m_{\mathrm{CO} 2}$ of ${ }^{14} \mathrm{CO}_{2}$ emissions:

$$
m_{\mathrm{CO}_{2}}(t)=\int_{V} \mathrm{CO}_{2}(x, t) d x
$$

296 with $V$ the volume of the soil cores. Mineralization at a given time $t$ was expressed as the

297 carbon mass of cumulated ${ }^{14} \mathrm{CO}_{2}$ emissions $\left(m_{\mathrm{CO}_{2}, q}(t)\right)$ per initial carbon mass of

$298{ }^{14} \mathrm{C}$-substrate $S\left(m_{S, q}(t=0)\right)$ where the index $q$ identifies the experiment at hand. Indices 
$2991,2,3$ and 4 are respectively given to the homogeneous hydrostatic, heterogeneous 300 hydrostatic, homogeneous percolation and heterogeneous percolation experiments. 301 Data-to-model adequacy was assessed for each of the experiments by a classical root-mean302 square evaluation function $J_{q}$ comparing the modeled mineralization of Eq. (4) to the 303 measured mineralization at the $n_{\mathrm{q}}$ available sampling times $t_{i}$ :

$$
J_{q}=\left(\frac{1}{n_{q}} \sum_{i=1}^{n_{q}}\left(\frac{m_{C O_{2}, q}^{m o d}\left(t_{i}\right)-m_{C O_{2}, q}^{\text {data }}\left(t_{i}\right)}{m_{S, q}(\mathrm{t}=0)}\right)^{2}\right)^{\frac{1}{2}}
$$

304 Discrepancies over the full set of experiments J1234 were thus expressed as:

$$
J_{1234}=\left(\frac{1}{4} \sum_{k=1}^{4} J_{k}^{2}\right)^{\frac{1}{2}}
$$

305 Following the systematic parameter screening described in section 2.4, the parameter set 306 minimizing J1234 was determined and referred to as the set calibrated on both hydrostatic 307 and percolation experiments. The measurement errors were in average 1.7 times higher in 308 the percolation experiments than in the hydrostatic experiments. This was assumed to be 309 due to differences in experimental setup between the two sets of experiments of Pinheiro 310 et al. $(2015,2018)$. This error difference contributed to limit the weight of the percolation 311 experiments when determining the best-fitting parameter set over the whole set of experiments $\left(J_{1234}\right)$. We made the choice to give an equal weight to all experiments by only 313 taking into account the average $\mathrm{CO}_{2}$ values. 


\section{Results}

\subsection{Model calibration}

316 The calibration of the bioreactive transport model carried out using only the hydrostatic 317 experimental data (Babey et al., 2017) led to a minimal discrepancy between data and model 318 of $J_{12}=0.023$ (Fig. 3-A1 and A2). This pre-existing parameterization was used to provide blind 319 predictions of the percolation experiments, with the effective dispersion coefficient $d_{\text {disp }}$ as an additional fitting parameter. It gave a reasonable prediction of mineralization in the

321 homogeneous percolation experiment $\left(J_{3}=0.038\right.$, Fig. $\left.3-\mathrm{A} 3\right)$ but failed in the heterogeneous 322 percolation experiment $\left(U_{4}=0.151\right.$, Fig. 3-A4), regardless of the dispersion coefficient values.

323 The smallest discrepancy $J_{4}$ was surprisingly obtained without any bacterial dispersion $324\left(d_{d i s p}=0\right)$ in contradiction with the bacterial spread observed in the experimental data 325 (Fig. S2). The final predicted mineralization was highest when bacteria remained aggregated 326 close to the initial location of the substrate. The highest predicted mineralization was 327 however four times lower than the experimental data. The large gap between the 328 experimental data and the modeled scenario suggests that bacterial proximity to the initial 329 substrate location is not the underlying explanatory mechanism for the high mineralization 330 rates. On the contrary, it suggests that mineralization might rather be increased by the 331 dispersion of bacteria towards more diluted substrate concentrations, and that the identified 332 bacterial traits do not match this increase of mineralization with dispersion. 

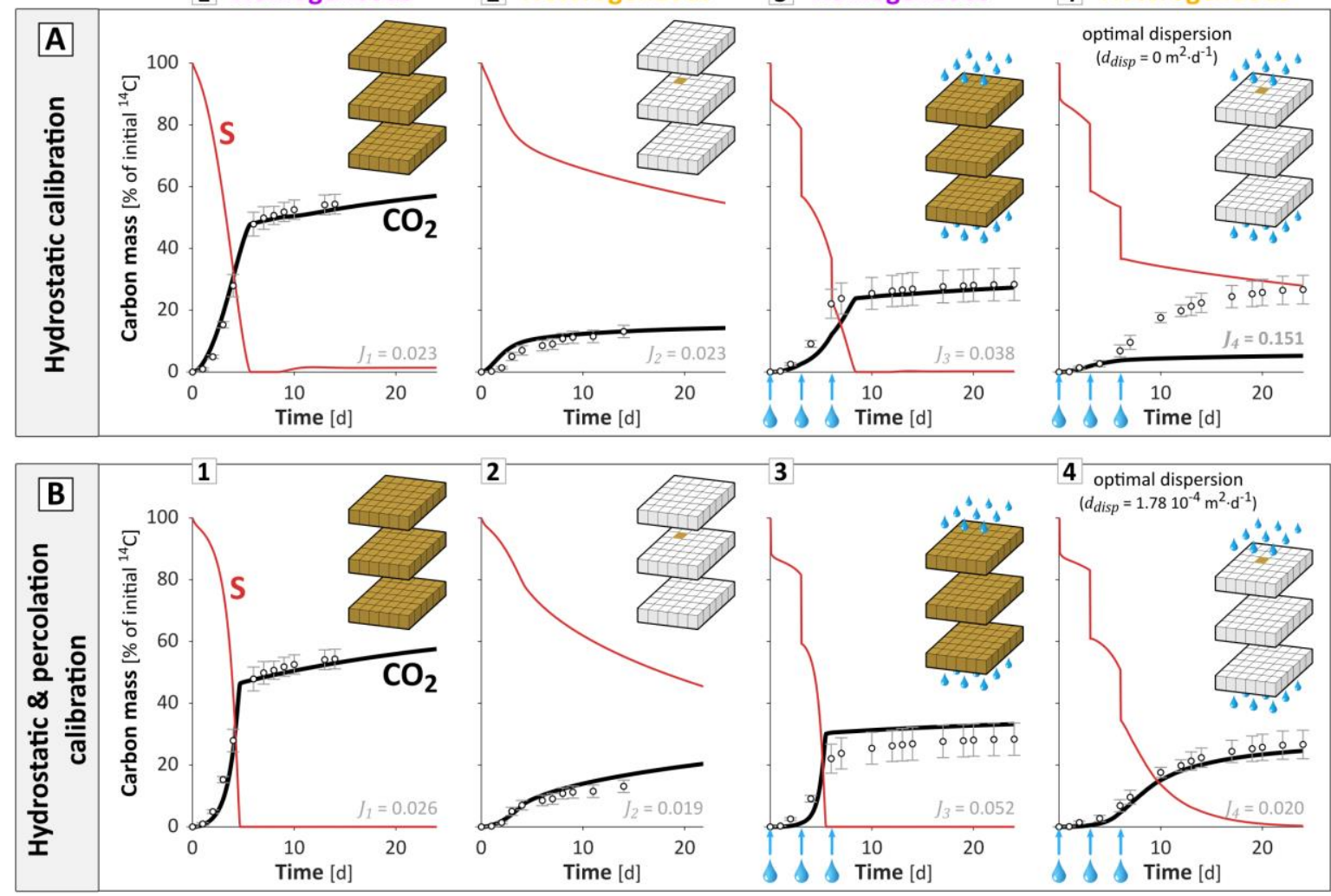

Fig. 3. Mineralization dynamics predicted with the Monod-based model calibrated on the hydrostatic experiment only (A) and on both hydrostatic and percolation experiments (B). The related experimental setups are indicated in the top right corner of each graph. The agreement between experiments and model is indicated by the value of discrepancy $J$ displayed at the bottom and can be visually assessed by the proximity between the black line and the dots representing respectively the model results and experimental data. The red line refers to the carbon mass of substrate remaining in the soil core. In the percolation experiments $(\mathbf{A} \mathbf{3}, \mathbf{4}$ and $\mathbf{B} 3, \mathbf{4})$, around $51 \%$ of the initial mass of ${ }^{14} \mathrm{C}$ was lost through leaching

342 after the three percolation events ( $t=0,3$ and 6 days, blue arrows). The carbon balance among the different pools is detailed in Fig. S11. Note that the reversible sorption eventually accounted for less than $2 \%$ of the initial carbon mass and therefore did not significantly alter the results.

In order to investigate the capacity of the reactive transport model to fit both hydrostatic and percolation experimental data, the biological parameters $\left((1 / y) \cdot \mu_{\max } / \kappa M,(1 / y) \cdot \mu_{\max }, \alpha\right.$, $B(t=0))$ and the dispersion coefficient $\left(d_{d i s p}\right)$ were calibrated on both hydrostatic and 
percolation experiments following the screening approach given in section 2.4 to minimize

J1234. The mineralization dynamics were adequately predicted in all four experiments with

351

the biological parameter set giving the lowest overall discrepancy $\left(J_{1234}=0.032\right)$ and a

352 non-zero dispersion coefficient $\left(d_{\text {disp }}=1.7810^{-4} \mathrm{~m}^{2} \cdot \mathrm{d}^{-1}\right)($ Fig. 3 and Table 2$)$. The non-zero

353

dispersion coefficient indicates that the calibrated model accounts for a positive impact of bacterial dispersion on degradation. The model results suggest that this effect is necessary

to successfully predict the high degree of degradation in the experimental data. Compared

to the parameters calibrated only using the hydrostatic experiments, the parameter set

calibrated on both hydrostatic and percolation experiments also displayed a much higher

358 maximum uptake efficiency $(1 / y) \cdot \mu_{\max } / \kappa_{M}=26.5 \mathrm{~g} \cdot \mu \mathrm{g}^{-1} \cdot \mathrm{d}^{-1}$ (mass of dry soil per mass of

359 bacterial carbon per unit of time) (Table 2). The systematic exploration of the parameter

360 space showed that high maximum uptake efficiency was a common feature of the $1 \%$

361 best-fitting parameterizations over both hydrostatic and percolation experiments (smallest

$362 \mathrm{~J} 1234)$, with values of 159 and $26.5 \mathrm{~g} \cdot \mu \mathrm{g}^{-1} \cdot \mathrm{d}^{-1}$, corresponding respectively to $1.7310^{4}$ and

$3632.8910^{3} \mathrm{I} \cdot \mathrm{g}^{-1} \cdot \mathrm{d}^{-1}$ (volume of water per mass of bacteria per unit of time). It underlines the

364 essential role of the maximum uptake efficiency for modulating the impact of dispersion on

365 degradation, further detailed and explained in section 3.2.3.

\section{Table 2.}

367 Parameters for the Monod-based model calibrated by the screening approach (section 2.2) 368 on the hydrostatic experiments only (Babey et al., 2017) and on both hydrostatic and 369 percolation experiments, and for the Contois-based model calibrated on both hydrostatic 370 and percolation experiments, as described in section 2.4 


\begin{tabular}{|c|c|c|c|c|c|}
\hline \multirow{2}{*}{\multicolumn{2}{|c|}{ Parameter symbol }} & \multirow[b]{2}{*}{ Unit } & \multicolumn{2}{|c|}{ Monod model calibration } & \multirow{2}{*}{$\begin{array}{c}\text { Contois } \\
\text { model } \\
\text { calibration } \\
\text { on both } \\
\text { hydrostatic \& } \\
\text { percolation } \\
\text { experiments }\end{array}$} \\
\hline & & & $\begin{array}{l}\text { on the sole } \\
\text { hydrostatic } \\
\text { experiments }\end{array}$ & $\begin{array}{c}\text { on both } \\
\text { hydrostatic \& } \\
\text { percolation } \\
\text { experiments }\end{array}$ & \\
\hline \multicolumn{2}{|c|}{$(1 / y) \cdot \mu_{\max }$} & $d^{-1}$ & 1.22 & 9.73 & 4.86 \\
\hline \multicolumn{2}{|c|}{$(1 / y) \cdot \mu_{\max } / \kappa^{a}$} & $\begin{array}{l}\mathrm{g} \cdot \mu \mathrm{g}^{-1} \cdot \mathrm{d}^{-1} \text { (mass of } \\
\text { dry soil per mass of } \\
\text { bacterial carbon per } \\
\text { unit of time) }\end{array}$ & $2.65^{b}$ & $26.5^{b}$ & $2.65^{b}$ \\
\hline \multicolumn{2}{|l|}{$\alpha$} & $d^{-1}$ & $9.34110^{-1}$ & $9.3410^{-2}$ & $9.3410^{-2}$ \\
\hline \multirow{2}{*}{$B(t=0$} & $\begin{array}{l}\text { Hydrostatic } \\
\text { experiments }\end{array}$ & $\begin{array}{l}\mu \mathrm{g} \cdot \mathrm{g}^{-1} \text { (mass of } \\
\text { bacterial carbon per } \\
\text { mass of } \mathrm{dry} \text { soil) }\end{array}$ & $1.6110^{-1}$ & $3.2310^{-2}$ & $3.7610^{-1}$ \\
\hline & $\begin{array}{l}\text { Percolation } \\
\text { experiments }\end{array}$ & $\mu g \cdot g^{-1}$ & $1.0110^{-1}$ & $2.0110^{-2}$ & $2.3410^{-1}$ \\
\hline \multicolumn{2}{|l|}{$d_{\text {disp }}$} & $m^{2} \cdot d^{-1}$ & $0^{c}$ & $1.7810^{-4} c$ & $10^{-5 c}$ \\
\hline \multicolumn{2}{|l|}{$J_{1234}$} & - & 0.079 & 0.032 & 0.022 \\
\hline
\end{tabular}

${ }^{a}$ The half-saturation constant $\kappa$ corresponds to $\kappa M$ for the Monod-based model and $372 B(t=0) \cdot \kappa c$ for the Contois-based model (where $B(t=0)$ is the value from the hydrostatic 373 experiments).

$374{ }^{b}$ Values of $(1 / y) \cdot \mu_{\max } / \kappa$ correspond respectively to $2.8910^{2}, 2.8910^{3}$ and $2.8910^{2} \mathrm{I} \cdot \mathrm{g}^{-1} \cdot \mathrm{d}^{-1}$ 375 (volume of water per mass of bacteria per unit of time).

$376{ }^{c}$ The corresponding spreading values induced by the hydrodynamic dispersion 377 (root-mean-square displacements) for each percolation events are respectively 0, 6.7 and $3781.6 \mathrm{~mm}$, to be compared to the $25 \mathrm{~mm}$ radius of the soil column.

379 3.2. Analysis of the controls exerted on degradation by substrate dilution and bacterial density

381 The effect of dispersion on degradation differed greatly between the two calibrated sets of 382 biological parameters described in section 3.1. We therefore conducted a more systematic 
investigation of the coupled impact of bacterial dispersion and bacterial traits on

384 degradation, revealing its control by substrate dilution and bacterial density.

\subsubsection{Impact of dispersion on degradation}

386 We used the mineralization at the end of the experimental time (day 24) as a proxy for 387 degradation and determined its sensitivity to dispersion, as a function of the 388 parameterization of bacterial traits. Fig. 4 shows the impact of the dispersion coefficient $d_{d i s p}$ 389 on the final predicted mineralization for the two calibrated biological parameter sets, all 390 other parameters being kept constant (thick red and blue lines). For the biological parameter 391 set calibrated on hydrostatic experiments, the final mineralization decreased monotonically 392 with dispersion (Fig. 4, red line). For the parameter set calibrated on both hydrostatic and 393 percolation experiments, the final mineralization first increased, reached a maximum around $394 d_{\text {disp }} \approx 10^{-4} \mathrm{~m}^{2} \cdot \mathrm{d}^{-1}$ and then decreased (Fig. 4, blue line). These two kinds of behaviors were 395 observed regardless of the parameters $\alpha,(1 / y) \cdot \mu_{\max }$ and $B(t=0)$ as long as $(1 / y) \cdot \mu_{\max } / \kappa_{M}$ 396 remained the same (Fig. S12). The non-monotonic impact of dispersion on degradation 397 highlights the existence of an optimal bacterial dispersion for which mineralization is the 398 highest. The comparison between the red and blue lines on Fig. 4 suggests that the optimal 399 dispersion value depends on the bacterial uptake efficiency. Note that, although the optimal 400 dispersion value varied with time due to the spatial dynamics of both bacteria and substrate 401 (Fig. S14), it tended towards a limit that was mostly reached within 4 to 7 days and is thus 402 represented at day 24 on Fig. 4. 


\section{Monod-based model}

403

404 Fig. 4. Influence of the dispersion coefficient $d_{\text {disp }}$ on mineralization predicted at day 24 405 406 407 408 409 $m_{\mathrm{CO} 2}(t=24)$ for the biological parameter set calibrated on the sole hydrostatic experiments ( $A$, thick red line) and on both hydrostatic and percolation experiments ( $B$, thick blue line). Note that for the model calibrated on both hydrostatic and percolation experiments, the value of $d_{d i s p}$ leading to the highest final mineralization $\left(d_{d i s p}=1.7810^{-4} \mathrm{~m}^{2} \cdot \mathrm{d}^{-1}\right.$, thick blue line) is also equal to its calibrated value leading to the best adequacy with mineralization kinetics (Table 2). Note that the optimal dispersion value remains the same when representing the remaining dissolved substrate instead of the mineralization (Fig. S13).

\subsubsection{Double control of degradation by substrate dilution and bacterial density}

The non-monotonic effect of bacterial dispersion on degradation is an unusual and key feature of the model calibrated on both hydrostatic and percolation experiments. In the following we will present an explanation for how such relationships between dispersion and degradation could arise, resulting from a non-monotonic spatial substrate profile, itself derived from the respective effects of substrate dilution and bacterial density.

In the model, the instant exposure of bacteria to their substrate is maximal if all the bacteria are located inside the voxel(s) with the highest substrate concentration. In the hydrostatic calibrated parameter set, the profile of substrate concentration primarily resulted from its initial heterogeneity (bell-shape red curve on Fig. 5A and pseudo bell-shape red curve on

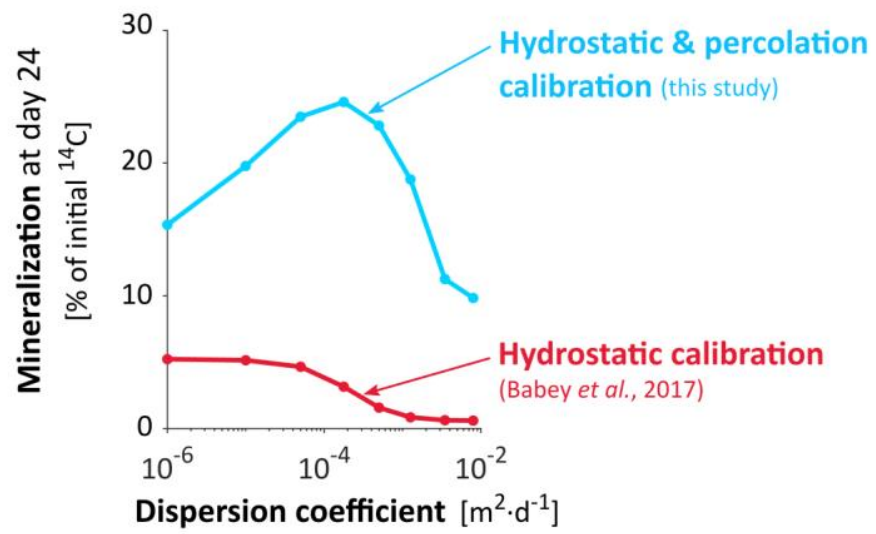


422 Fig. 5B). The flux of substrate reaching each bacterium was therefore mostly determined by

423 the distance between the bacterium and the initial location of substrate. The exposure of a

424 single bacterium to the substrate decreased with its distance from the substrate initial

425 location. This effect is referred to as "substrate dilution". In these cases (Fig. 5A and B),

426 mineralization was mainly regulated by substrate dilution, and therefore reduced by

427 bacterial dispersion (Fig. 4, blue line). However, for the parameter set calibrated on both

428 hydrostatic and percolation experiments, local degradation by aggregated bacteria reshaped

429 the substrate spatial profile, thus critically changing the voxel(s) with the highest substrate

430 concentration. The bacteria aggregated at their initial location consumed the substrate much

431 faster than it was replenished by backward diffusion and dispersion, creating a critical

432 inversion of the substrate gradient, which led to an intra-population competition for

433 substrate (Fig. 5C). The competition was critical for bacterial densities as small as $3.510^{-3}$

$434 \mathrm{~g} \cdot \mathrm{l}^{-1}$ (Fig. 5C). In contrast, the dispersion of bacteria reduced competition by diluting the

435 highest bacterial densities, thus flattening the substrate gradient inversion induced by

436 bacterial local degradation, resulting in a better overall exposure of bacteria to the substrate

437 concentrations, and thus an enhanced mineralization (Fig. 5D). In these cases (Fig. 5C and D),

438 mineralization was mainly regulated by bacterial density, or in other words by the distances

439 among bacteria. The relationship between bacterial density and the limitation of their

440 exposure to the substrate is not instantaneous and is mediated by the local depletion of the

441 substrate concentration. This is expressed in the model equations through the dependence

442 of bacterial activity $\mu(t)$ on substrate concentration $S(t)$ (Eq. (7)) and the dependence of the

443 substrate concentration $S(t)$ on degradation $\mu(t) \cdot B(t)$ (Eq. (1)), within each voxel. However,

444 when bacterial dispersion was too great, substrate dilution became the dominant control

445 again. This suggests that an optimal bacterial spatial spread exists for which the dilution of 
446 substrate is compensated by the dilution of high local bacterial densities. The modeled

447 scenario illustrated by the two calibrated parameter sets were also observed for most of the 448 other parameter sets. The optimal dispersion coefficient for the 300 best-fitting 449 parameterizations to both hydrostatic and percolation experiments (smallest $J_{1234}$ values) 450 was on average $d_{\text {disp }} \approx 210^{-5} \mathrm{~m}^{2} \cdot \mathrm{d}^{-1}$ (Fig. S15), corresponding to a root-mean-square 451 displacement of bacteria of $2.2 \mathrm{~mm}$ during each percolation event.
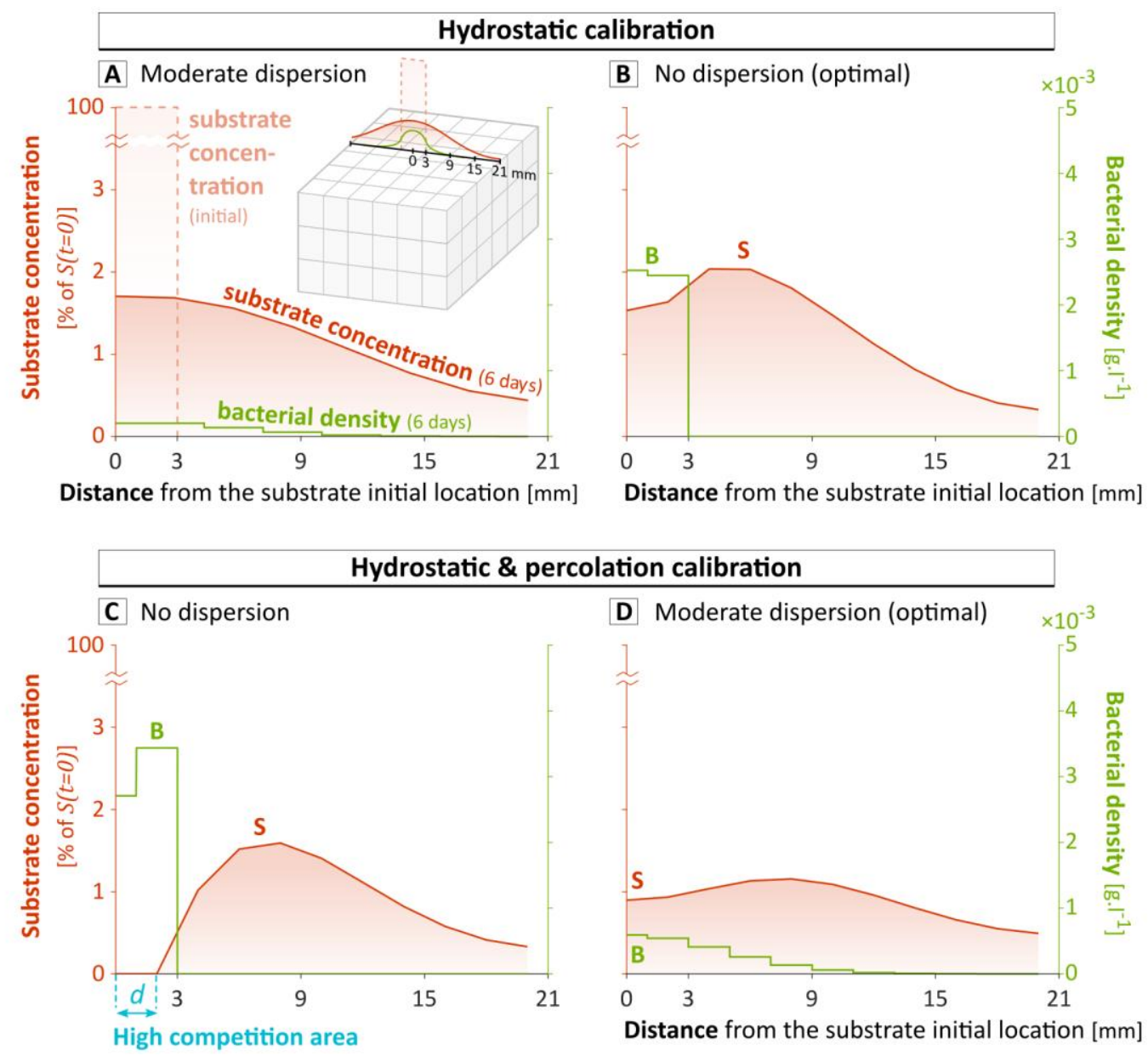

452

453

454

455

456

457

458

459

Fig. 5. Predicted substrate and bacterial spatial concentration profiles after6 days of diffusion and dispersion in the conditions of heterogeneous percolation experiment, in which bacteria and substrate are initially located exclusively in the central cube (from 0 to $3 \mathrm{~mm}$ ). Results are simulated on a $9 \times 18 \times 18$ grid obtained by subdividing the $3 \times 6 \times 6$ grid used for the screenings. The results are represented for the parameter set calibrated using only the sole hydrostatic experiment, either with a moderate dispersion ( $d_{\text {disp }}=1.7810^{-4}$ $\left.\mathrm{m}^{2} \cdot \mathrm{d}^{-1}\right)(\mathbf{A})$ or with the calibrated dispersion (no dispersion) (B), and for the biological 
460

461

462

463

464

465

466

467

468

469

470

471

472

473

474

475

476

477

478

479

480

481

482

483

484

485

parameter set calibrated on both hydrostatic and percolation experiments, either without dispersion (C) or with the calibrated dispersion $\left(d_{d i s p}=1.7810^{-4} \mathrm{~m}^{2} \cdot \mathrm{d}^{-1}\right)(\mathbf{D})$. On one hand, bacteria are exposed to smaller substrate concentrations if they are far from the source (right part of the substrate concentration profiles). On the other hand, bacteria undergo competition if they are too close from each other (left part of the substrate concentration profiles). In (C), the bacteria aggregated below $d$ consume the substrate faster than it is replenished by backward diffusion and dispersion. The total number of bacteria within the whole soil column at day 6 is similar in (A), (B), (C) and (D), respectively equal to $6.010^{5}$, $9.510^{5}, 11.510^{5}$ and $11.310^{5}$. The final mineralization at day 24 is however strongly different between scenario, reaching respectively $3.2 \%, 5.3 \%, 9.1 \%$ and $24.7 \%$ of the initial mass of ${ }^{14} \mathrm{C}$.

\subsubsection{Effect of bacterial uptake efficiency on the impact of dispersion on degradation}

A non-monotonic substrate concentration profile only occurs when bacterial degradation locally depletes the substrate faster than it is replenished by diffusion. This area of high local competition for substrate results from either high local densities of bacteria or high competitiveness or both. Bacterial competitiveness is related to their maximum uptake efficiency $(1 / y) \cdot \mu_{\max } / \kappa_{M}$, which also describes their capacity to maintain their activity and growth under dilute substrate concentrations (Healey, 1980; Button, 1991; Lobry et al., 1992). Bacteria with high maximum uptake efficiency are thus expected to benefit more from dispersion. Fig. 6 shows the optimal dispersion coefficient as a function of the maximum uptake efficiency, with all other parameters equal to those of the model calibrated on both hydrostatic and percolation experiments. The optimal dispersion coefficient, defined as the dispersion coefficient maximizing the final mineralization, increased with the maximum uptake efficiency. For small maximum uptake efficiencies of $30 \mathrm{I} \cdot \mathrm{g}^{-1} \cdot \mathrm{d}^{-1}$ and below, mineralization was highest in the absence of dispersion, suggesting a regulation dominated by substrate dilution. For larger maximum uptake efficiencies, dispersion impacted positively 
486

487

488 to all parameterizations (Fig. S16).

493

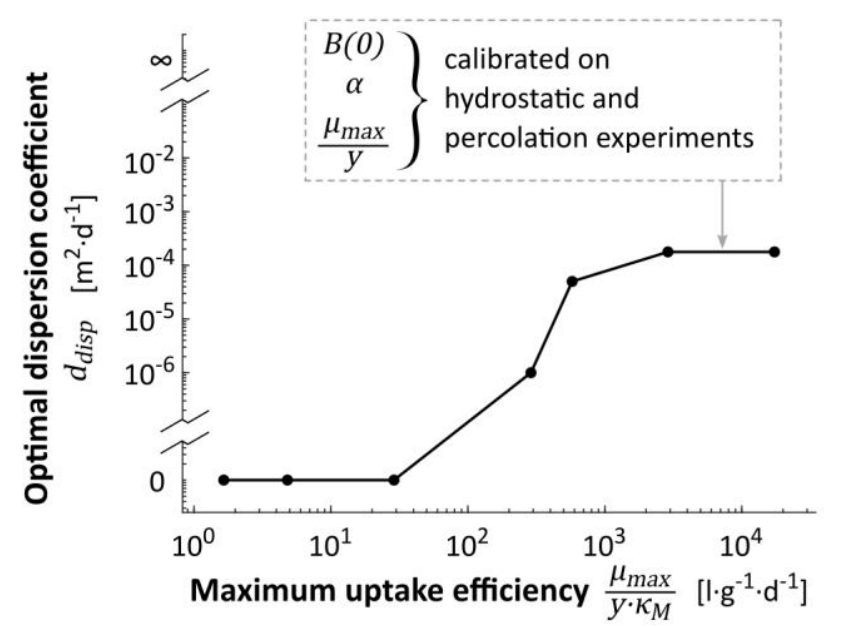

494 Fig. 6. Dispersion coefficient giving the highest predicted mineralization at day 24 as a 495 function of maximum uptake efficiency, all other parameters equal to those of the model 496 calibrated on both hydrostatic and percolation experiments. applying the calibration methodology of section 2.5 , as used in section 3.1 . The interest in

mineralization, suggesting that degradation shifted from being regulated by substrate dilution to being regulated by bacterial densities, as bacteria were both more prone to competition between themselves and more efficient under diluted substrate conditions. In other words, the proximity to other bacteria constrained activity more than the proximity to the substrate initial location enhanced it. This combined effect of the maximum uptake efficiency and the bacterial dispersion on degradation was a general relationship common

\subsection{The Contois-based model as an alternative to Monod}

Given that degradation is regulated by both substrate dilution and bacterial density, and that their relative importance is modulated by bacterial uptake efficiency at the lowest substrate concentration, $(1 / y) \cdot \mu_{\max } / \kappa_{M}$, we investigated the relevance of the Contois model by applying the calibration methodology of section 2.5, as used in section 3.1. The interest in the Contois growth law (Eq. (8)) stems from the inclusion of a regulation by density in the 
expression of the uptake efficiency at the lowest substrate concentration, becoming $504(1 / y) \cdot \mu_{\max } /(B(t) \cdot \kappa c)$

505 In comparison with the Monod-based model, the predictions of the experimental 506 observations of Pinheiro et al. $(2015,2018)$ were facilitated with the Contois-based model, 507 on three levels. First, the Contois-based model captured the degradation dynamics better 508 than the Monod-based model, especially for the $1 \%$ best-fitting parameterizations (smallest 509 J1234 values) (Fig. S17). The calibrated Contois-based model had an overall discrepancy of $510 J_{1234}=0.022$ (Fig. 7), which was smaller than the lowest value of $J_{1234}=0.032$ obtained for

511 the calibrated Monod-based model (Fig. 3).

\section{HYDROSTATIC}

1 Homogeneous

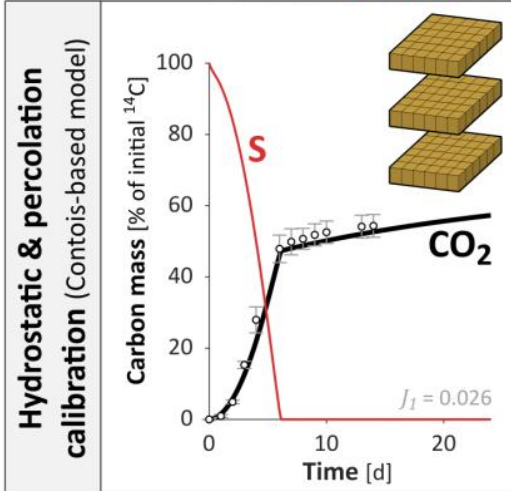

2 Heterogeneous

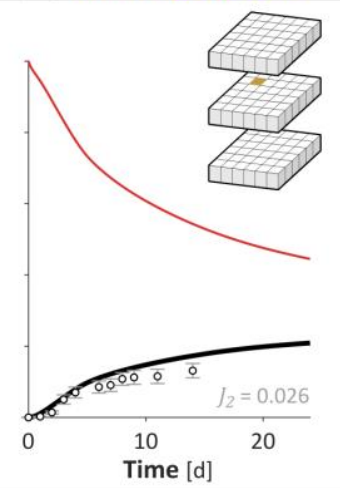

PERCOLATION

3 Homogeneous 4 Heterogeneous

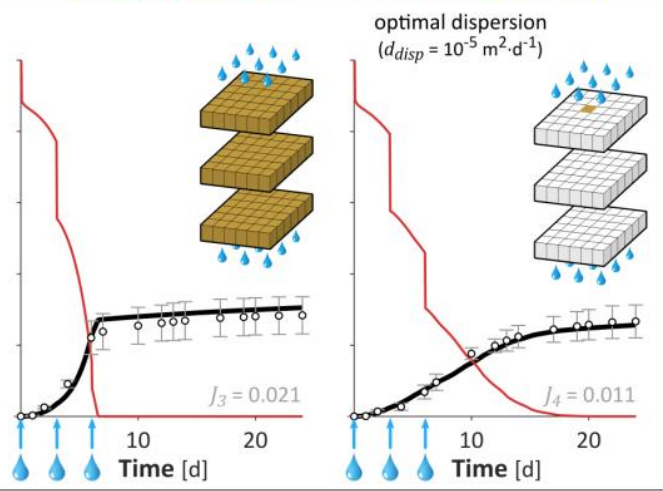

513 Fig. 7. Mineralization dynamics predicted with the Contois-based model calibrated on both

514 hydrostatic and percolation experiments. For representation and legend, see Fig. 3. The 515 carbon balance among the different pools is detailed in Fig. S11.

516 Second, the parameter sets that fitted homogeneous experiments also performed well 517 under heterogeneous conditions, as long as the dispersion coefficient $d_{d i s p}$ was calibrated as 518 well (Fig. S18). It is an important advantage as it confers a better capacity to predict 519 degradation kinetics for heterogeneous and varying distributions, once the model is 520 calibrated in homogeneous conditions, which are more appropriate for the experimental 
521 measurement of bacterial parameters. Besides, using a dispersion coefficient value different

522 from the calibrated one weakened the predictions of the mineralization dynamics but not

523 the predictions of the mineralization after 24 days, which remained satisfying regardless of

524 the dispersion coefficient. More precisely, the prediction of the final mineralization became

525 mostly independent of the dispersion coefficient, as shown for the calibrated model (Fig. 8).

526 This is because, in the Contois model at low substrate concentrations, the number of active

527 bacteria in a soil volume is exactly counterbalanced by the regulation of their uptake

528 efficiency by population density (Eq. (8)), resulting in limited effects of bacterial spreading

529 on overall mineralization (Fig. 8, constant part of the curves).

\section{Contois-based model}

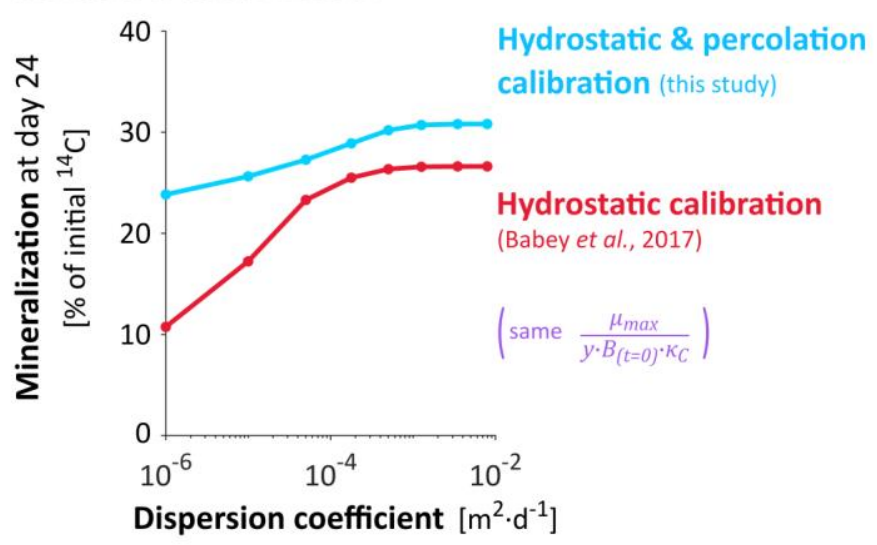

530

531 Fig. 8. Influence of the dispersion coefficient on mineralization at day 24 for the

532 Contois-based models calibrated on the sole hydrostatic experiments (thick red line) and on

533 both hydrostatic and percolation experiments (thick blue line). For representation and 534 legend, see Fig. 4. 


\section{Discussion}

536

538

539

540

541

542

555 competition became critical were around $3.510^{-3} \mathrm{~g} \cdot \mathrm{I}^{-1}$, corresponding to $7.510^{-7} \mathrm{~g} \cdot \mathrm{g}$ (mass 556 of bacteria per mass of dry soil), ranging in the low end of usual total soil bacterial densities

\subsection{Relevance of density control for 2,4-D degradation and soil carbon cycling}

\subsubsection{Density control of soil oligotroph bacteria}

Bulk soil and highly-diluted environments are usually found to be dominated by bacteria with high maximum uptake efficiency, also called oligotrophs (Fierer et al., 2007; Nunan et al., 2020). Their high maximum uptake efficiency differentiates their life-history strategies and conditions their ability to thrive in resource poor environments (Button, 1993), also assimilated to K-strategy (Tecon and Or, 2017), by opposition to copiotrophic bacteria adapted to rich environments ( $r$-strategy). The maximum uptake efficiency values of the $1 \%$ best-fitting parameter sets were of the order of $10^{3}-10^{4} \mathrm{I} \cdot \mathrm{g}^{-1} \cdot \mathrm{d}^{-1}$ (volume of water per mass of bacteria per unit of time), within the range proposed by Button (1991) to define oligotrophs. Similar or higher maximum uptake efficiency values of the order of $10^{4}-10^{5} \mathrm{I} \cdot \mathrm{g}^{-1} \cdot \mathrm{d}^{-1}$ have been reported for soil oligotrophs (Ohta and Taniguchi, 1988; Zelenev et al., 2005). Values up to $1.6410^{5}$ have been reported by Tuxen et al. (2002) for 2,4-D degraders in an aerobic aquifer and even greater values might also be possible (see section S5). The high maximum uptake efficiencies predicted in section 3.1 for the best-fitting parameterizations are therefore a plausible bacterial trait among 2,4-D degraders as well as bulk soil bacteria in general. It suggests that density control might be relevant for a component of soil bacteria, which would benefit from dispersion as suggested by Fig. 6 . The calibrated model has shown in section 3.2.2 that the values of densities from which 
557 (Raynaud and Nunan, 2014; Kuzyakov and Blagodatskaya, 2015). This suggests that 558 competition might play a significant role even under the low bacterial densities observed in 559 bulk soils, at least in similar substrate conditions. Reciprocally, the model suggests that 560 competition for substrate between copiotrophic bacteria only appears at much larger 561 population densities, such as those found in soil biofilms (Holden et al., 1997, Or et al., 2007). 562 Interestingly, copiotrophic bacteria have been reported to cohabit with oligotrophic bacteria 563 even in diluted environments (Gözdereliler et al., 2013). Results from the screening suggest 564 that, for densities of copiotrophs as low as for oligotrophs, their impact on overall 565 decomposition in dilution-dominated environments would be much lower due to their 566 poorly adapted uptake efficiency (Fig. 4A). Conversely, this striking density regulation might 567 be one of the main limitations of the overall population densities in soils. Note that this 568 density regulation occurs within a single population with homogeneous biological constants. 569 Spatial heterogeneities and low substrate concentrations, common in bulk soil, may indeed 570 shift competition from the inter-population level to the intra-population level (Pfeiffer et al., 571 2001; Roller and Schmidt, 2015).

\subsubsection{A new perspective on Regulatory Gate hypothesis}

573 Density regulation might partially contribute to explain the common paradox of the apparent

574 uncoupling between the overall mineralization of a soil volume and the size of its microbial 575 population (Kemmitt et al., 2008). The rate of soil carbon mineralization remains the same 576 even if $90 \%$ of the microbial decomposers are killed. This observation is commonly explained 577 by the Regulatory Gate hypothesis, where mineralization is assumed to be controlled by an 578 abiotic process, such as desorption or diffusion, that limits the availability of the substrate, 579 resulting in mineralization rates that are independent of the degrader abundance. We 
580

581

582

583

584

585

586

$$
\text { section 3.2), is well limiting but only in situations of high bacterial competition. }
$$

\section{7}

\subsection{Relevance of the ratio-dependent Contois model in soils}

As argued in section 3.3, ratio-dependence might facilitate decomposition modeling in the

589 soil conditions typical of the experiments analyzed here. The Contois model's

$590(1 / y) \cdot \mu_{\max } /(\kappa c \cdot B)$ calibrated in homogeneous conditions might be used in heterogeneous

591 conditions more reliably than the Monod model's $(1 / y) \cdot \mu_{\max } / \kappa_{M}$, at least for soil systems in

592 which the competition for the substrate plays a substantial role within the degrader

593 population. The similarity between $\kappa_{M}$ and $\kappa c B$ suggests the need to consider population

594 density when measuring the apparent maximum uptake efficiency of soil bacteria to avoid

595 underestimating it by unintentionally including density regulation. Moreover, the better

596 predictions obtained with the Contois model in the soil conditions represented by the

597 experiments suggest that the Contois ratio-dependence includes not only the effect of

598 competition for substrate at the scale of measurement, but it can also reasonably reflect

599 other density processes such as the spatial variability of bacterial distributions at finer scales

600 related to their high degree of local aggregation in microcolonies (Raynaud and Nunan,

601 2014). Moreover, ratio-dependence may also include the cumulative effects of ecological 
602 interactions other than competition (Sibly and Hone, 2002). Note that the methodological

603 approach used in this study for both Monod and Contois models is based on an effective 604 representation of concentrations and parameters at the $\mathrm{mm}$ - to $\mathrm{cm}$-scale of measurements.

605 These effective concentrations and parameters conceptually integrate the smaller-scale 606 processes highlighted by other studies (Ebrahimi and Or, 2014; Portell et al., 2018; Tecon et 607 al., 2018). Such microscale processes should be addressed for further generalization beyond 608 the conditions of the soil experiments analyzed here. Despite its advantages, Contois models 609 have also a drawback with the fact that the modeled uptake efficiency of bacteria 610 approaches infinity for low densities, which does not correspond to any physical nor 611 biochemical process (Gleeson, 1994; Abrams, 2015). However, this side effect mostly affects 612 a negligible fraction of the bacteria and the substrate, as it was the case in the soil conditions 613 represented by the experiments.

614 Further work is required to confront the relevance of the Contois model to other soil 615 systems. To the best of our knowledge, ratio-dependent growth models such as the Contois 616 model have not yet been considered for the modeling of microbial degradation in soils.

617 However, the Contois growth equation is generally accepted to be more appropriate than 618 the Monod equation for modeling immobilized, heterogeneously distributed or mixed 619 microbial cultures (Arditi and Saiah, 1992; Harmand and Godon, 2007), all of which are 620 characteristics of soils. The regulation of individual activity by population density has 621 frequently been justified as a "crowding effect" associated with high population densities 622 leading to competition for substrate (Lobry and Harmand, 2006; Harmand and Godon, 2007; 623 Krichen et al., 2018). However, little is known about possible density regulation when 624 apparent microbial densities are low, as is observed in bulk soil (Raynaud and Nunan, 2014; 
625 Kuzyakov and Blagodatskaya, 2015), although some studies have mentioned

626 ratio-dependence in highly-diluted environments such as aquifers (Hansen et al., 2017). As

627 discussed in section 4.1.1, the high maximum uptake efficiencies commonly observed for soil

628 bacteria adapted to oligotrophic environments are relevant to draw attention on the

629 potential significance of density control at low densities in oligotrophic soils, and thus

630 ratio-dependent models, among which the Contois model is a consistent choice.

631 4.3. Hypothetical relationship between bacterial traits and their spatial

632 strategies

633 Density regulation might be at the origin of a relationship between bacterial oligotrophy,

634 their location in soil and their mobility strategy. Soil copiotroph bacteria have a maximum

635 uptake efficiency mostly between $100 \mathrm{I} \cdot \mathrm{g}^{-1} \cdot \mathrm{d}^{-1}$ (Button, 1991) and $800 \mathrm{I} \cdot \mathrm{g}^{-1} \cdot \mathrm{d}^{-1}$ (Daugherty

636 and Karel, 1994; Zelenev et al., 2005). For copiotrophs with maximum uptake efficiency

637 values below $288 \mathrm{I} \cdot \mathrm{g}^{-1} \cdot \mathrm{d}^{-1}$, bacterial dispersion was largely detrimental to their activity (Fig. 4

638 blue line, Fig. 6), in agreement with the results of Pagel et al. (2020), suggesting that

639 copiotrophs have more aggregated distributions than oligotrophs. The negligible

640 mineralization even without dispersion (Fig. 3-A4) also highlights the fact that copiotrophs

641 are particularly inefficient at degrading substrates that diffuse in the environment, as also

642 evidenced by Babey et al. (2017). To maintain significant activity, soil copiotrophs are likely

643 to remain immobile in the close surroundings of the substrate source or any immobile

644 substrate, likely attached to surfaces or embedded in EPS matrices. If not, they would be

645 dispersed towards more diluted area where their low maximum uptake efficiency would

646 result in negligible uptake. On the contrary, to survive and develop, soil oligotrophs should 
647 be able to easily disperse and escape high competition areas. Given that soil is a poor and

648 heterogeneous environment, this dispersion would be essentially passive (Nunan et al., 649 2020), through advective processes for example. We therefore suggest the existence of a 650 theoretical relationship between proximity to substrate sources (respectively remoteness), 651 copiotrophy (respectively oligotrophy) and attachment (respectively mobility).

\section{5. Conclusions}

653 Heterogeneous distributions of degraders and substrate in soils strongly control soil organic 654 matter degradation through their interactions with the bacterial activity. Taking 2,4-D as a 655 model organic solute substrate for soil bacteria, we investigated the coupled effects of 656 bacteria and substrate distributions on one side and bacterial traits on the other side on 657 substrate degradation. The analysis of published experiments with contrasted spreading 658 conditions of both bacteria and substrate reveals that, in addition to the distance of bacteria 659 from high substrate concentrations, mineralization is also surprisingly limited by the 660 bacterial density even under the low bacterial densities commonly observed in bulk soils.

661 Moreover, the impact of bacterial dispersion on solute substrate degradation can shift from 662 negative to positive depending on the bacterial maximum uptake efficiency. The activity of 663 soil oligotrophs may be mostly regulated by bacterial density rather than by substrate 664 dilution, echoing the population size paradox regularly observed. It follows that the 665 ratio-dependent Contois model might be more relevant to model bulk soil mineralization in 666 the heterogeneous conditions investigated than the substrate-dependent Monod model. To 667 predict the impact of spatial distributions on degradation in oligotrophic soil, and more 668 particularly the impact of bacterial dispersion, we suggest that bacterial densities might be 
a more useful measurement than the volumes of soil devoid or occupied with bacteria. With

670 respect to the current lack of direct microscale data on microbial processes and distributions,

671 we propose some key perspectives on the bacterial kinetics and distributions.

672 Acknowledgements

673 This work was supported by the Agence Nationale de la Recherche through the project

674 "Soilu-3D" [grant number ANR-15-CE01-0006] and was also partially supported by the SLAC

675 Floodplain Hydro-Biogeochemistry Science Focus Area (SFA), which is funded by the U.S.

676 Department of Energy (DOE) office of Biological and Environmental Research (BER), Climate

677 and Environmental Sciences Division, under DOE contract No. DE- AC02-76SF00515 to SLAC.

678 The authors thank Jérôme Harmand, Théodore Bouchez, Xavier Raynaud, Tanguy Le Borgne,

679 Claire Chenu and Holger Pagel for insightful discussions. The authors would also like to thank

680 the two anonymous referees and the editor for their constructive and valuable comments.

681 Appendix A. Supplementary Data

682 References

683 Abrams, P.A., 2015. Why ratio dependence is (still) a bad model of predation: Ratio-

684 dependent predation. Biological Reviews 90, 794-814.

685 https://doi.org/10.1111/brv.12134

686 Arditi, R., Saiah, H., 1992. Empirical evidence of the role of heterogeneity in ratio-

687 dependent consumption. Ecology 73, 1544-1551. https://doi.org/10.2307/1940007 
688

689

690

691

692

693

694

695

696

697

698

699

700

701

702

703

704

705

706

707

708

709

710

Babey, T., Vieublé Gonod, L., Rapaport, A., Pinheiro, M., Garnier, P., de Dreuzy, J.-R., 2017. Spatiotemporal simulations of 2,4-D pesticide degradation by microorganisms in 3D soil-core experiments. Ecological Modelling 344, 48-61. https://doi.org/10.1016/j.ecolmodel.2016.11.006

Bælum, J., Henriksen, T., Hansen, H.C.B., Jacobsen, C.S., 2006. Degradation of 4-chloro-2methylphenoxyacetic acid in top- and subsoil is quantitatively linked to the class III tfdA gene. Applied and Environmental Microbiology 72, 1476-1486. https://doi.org/10.1128/AEM.72.2.1476-1486.2006

Bælum, J., Nicolaisen, M.H., Holben, W.E., Strobel, B.W., Sørensen, J., Jacobsen, C.S., 2008. Direct analysis of $\mathrm{tfdA}$ gene expression by indigenous bacteria in phenoxy acid amended agricultural soil. The ISME Journal 2, 677-687. https://doi.org/10.1038/ismej.2008.21

Boivin, A., Amellal, S., Schiavon, M., van Genuchten, M.Th., 2005. 2,4dichlorophenoxyacetic acid (2,4-D) sorption and degradation dynamics in three agricultural soils. Environmental Pollution 138, 92-99. https://doi.org/10.1016/j.envpol.2005.02.016

Breitenbeck, G.A., Yang, H., Dunigan, E.P., 1988. Water-facilitated dispersal of inoculant Bradyrhizobium japonicum in soils. Biology and Fertility of Soils 7, 58-62. https://doi.org/10.1007/BF00260733

Bünemann, E.K., Bongiorno, G., Bai, Z., Creamer, R.E., De Deyn, G., de Goede, R., Fleskens, L., Geissen, V., Kuyper, T.W., Mäder, P., Pulleman, M., Sukkel, W., van Groenigen, J.W., Brussaard, L., 2018. Soil quality - A critical review. Soil Biology and Biochemistry 120, 105-125. https://doi.org/10.1016/j.soilbio.2018.01.030 
711 Button, D.K., 1978. On the theory of control of microbial growth kinetics by limiting

712

713

714

715

716

717

718

719

720

721

722

723

724

725

726

727

728

729

730

731

732

nutrient concentrations. Deep Sea Research 25, 1163-1177.

https://doi.org/10.1016/0146-6291(78)90011-5

Button, D.K., 1983. Differences between the kinetics of nutrient uptake by microorganisms, growth and enzyme kinetics. Trends in Biochemical Sciences 8, 121-124. https://doi.org/10.1016/0968-0004(83)90232-3

Button, D.K., 1991. Biochemical basis for whole-cell uptake kinetics: specific affinity, oligotrophic capacity, and the meaning of the michaelis constant. Applied and Environmental Microbiology 57, 2033-2038.

Button, D.K., 1993. Nutrient-limited microbial growth kinetics: overview and recent advances. Antonie van Leeuwenhoek 63, 225-235. https://doi.org/10.1007/BF00871220

Carrayrou, J., Mosé, R., Behra, P., 2004. Operator-splitting procedures for reactive transport and comparison of mass balance errors. Journal of Contaminant Hydrology 68, 239-268. doi:10.1016/S0169-7722(03)00141-4

Cheyns, K., Mertens, J., Diels, J., Smolders, E., Springael, D., 2010. Monod kinetics rather than a first-order degradation model explains atrazine fate in soil mini-columns: Implications for pesticide fate modelling. Environmental Pollution 158, 1405-1411. https://doi.org/10.1016/j.envpol.2009.12.041

Contois, D.E., 1959. Kinetics of bacterial growth: relationship between population density and specific growth rate of continuous cultures. Journal of General Microbiology 21, 40-50. https://doi.org/10.1099/00221287-21-1-40 
733 Daugherty, D.D., Karel, S.F., 1994. Degradation of 2,4-dichlorophenoxyacetic acid by

734

735

736

737

738

739

740

741

742

743

744

745

746

747

748

749

750

751

752

753

754 Pseudomonas cepacia DBOI(pRO101) in a dual-substrate chemostat. Applied and Environmental Microbiology 60, 3261-3267.

Dechesne, A., Owsianiak, M., Bazire, A., Grundmann, G.L., Binning, P.J., Smets, B.F., 2010. Biodegradation in a partially saturated sand matrix: compounding effects of water content, bacterial spatial distribution, and motility. Environmental Science \& Technology 44, 2386-2392. https://doi.org/10.1021/es902760y

Dechesne, A., Badawi, N., Aamand, J., Smets, B.F., 2014. Fine scale spatial variability of microbial pesticide degradation in soil: scales, controlling factors, and implications. Frontiers in Microbiology 5, 667. https://doi.org/10.3389/fmicb.2014.00667

Desmond-Le Quéméner, E., Bouchez, T., 2014. A thermodynamic theory of microbial growth. The ISME Journal 8, 1747-1751. doi:10.1038/ismej.2014.7

Don, R.H., Weightman, A.J., 1985. Transposon mutagenesis and cloning analysis of the pathways for degradation of 2,4-dichlorophenoxyacetic acid and 3-chlorobenzoate in Alcaligenes eutrophus JMP134(pJP4). Journal of Bacteriology 161, 85-90.

Ebrahimi, A.N., Or, D., 2014. Microbial dispersal in unsaturated porous media: Characteristics of motile bacterial cell motions in unsaturated angular pore networks. Water Resources Research 50, 7406-7429. doi:10.1002/2014WR015897

Fierer, N., Bradford, M.A., Jackson, R.B., 2007. Toward an ecological classification of soil bacteria. Ecology 88, 1354-1364. https://doi.org/10.1890/05-1839

Gleeson, S.K., 1994. Density dependence is better than ratio dependence. Ecology 75, 1834-1835. https://doi.org/10.2307/1939642 
755 Gözdereliler, E., Boon, N., Aamand, J., De Roy, K., Granitsiotis, M.S., Albrechtsen, H.J.,

756

757

758

759

760

761

762

763

764

765

766

767

768

769

770

771

772

773

774

775

776
Sørensen, S.R., 2013. Comparing metabolic functionalities, community structures and dynamics of herbicide-degrading communities with different substrate concentrations. Applied and Environmental Microbiology 79 (1), 367-375. https://doi.org/10.1128/AEM.02536-12

Hansen, S.K., Pandey, S., Karra, S., Vesselinov, V.V., 2017. CHROTRAN: A mathematical and computational model for in situ heavy metal remediation in heterogeneous aquifers. ArXiv:1703.01381 [q-Bio].

Harmand, J., Godon, J.J., 2007. Density-dependent kinetics models for a simple description of complex phenomena in macroscopic mass-balance modeling of bioreactors. Ecological Modelling 200, 393-402. https://doi.org/10.1016/j.ecolmodel.2006.08.012

Healey, F.P., 1980. Slope of the Monod equation as an indicator of advantage in nutrient competition. Microbial Ecology 5, 281-286. http://www.jstor.org/stable/4250586

Holden, P.A., Firestone, M.K., 1997. Soil microorganisms in soil cleanup: How can we improve our understanding? Journal of Environment Quality 26, 32-40. https://doi.org/10.2134/jeq1997.00472425002600010006x

Holden, P.A., Hunt, J.R., Firestone, M.K., 1997. Toluene diffusion and reaction in unsaturated Pseudomonas putida biofilms. BIOTECHNOLOGY AND BIOENGINEERING 56, 15.

Iserles, A., 2009. A first course in the numerical analysis of differential equations, Cambridge University Press. ed. 
777 Kemmitt, S.J., Lanyon, C.V., Waite, I.S., Wen, Q., Addiscott, T.M., Bird, N.R.A., O'Donnell,

778

779

780

781

782

783

784

785

786

787

788

789

790

791

792

793

794

795

796

797

A.G., Brookes, P.C., 2008. Mineralization of native soil organic matter is not regulated by the size, activity or composition of the soil microbial biomass - a new perspective. Soil Biology and Biochemistry 40, 61-73.

https://doi.org/10.1016/j.soilbio.2007.06.021

König, S., Vogel, H.-J., Harms, H., Worrich, A., 2020. Physical, chemical and biological effects on soil bacterial dynamics in microscale models. Frontiers in Ecology and Evolution 8, 53. https://doi.org/10.3389/fevo.2020.00053

Krichen, E., Harmand, J., Torrijos, M., Godon, J.J., Bernet, N., Rapaport, A., 2018. High biomass density promotes density-dependent microbial growth rate. Biochemical Engineering Journal 130, 66-75. https://doi.org/10.1016/j.bej.2017.11.017

Kuzyakov, Y., Blagodatskaya, E., 2015. Microbial hotspots and hot moments in soil: Concept \& review. Soil Biology and Biochemistry 83, 184-199. https://doi.org/10.1016/j.soilbio.2015.01.025

Lagneau, V., van der Lee, J., 2010. Operator-splitting-based reactive transport models in strong feedback of porosity change: The contribution of analytical solutions for accuracy validation and estimator improvement. Journal of Contaminant Hydrology 112, 118-129. doi:10.1016/j.jconhyd.2009.11.005

Lobry, C., Harmand, J., 2006. A new hypothesis to explain the coexistence of $n$ species in the presence of a single resource. Comptes Rendus Biologies 329, 40-46. https://doi.org/10.1016/j.crvi.2005.10.004 
798

799

800

801

802

803

804

805

806

807

808

809

810

811

812

813

814

815

816

817

818

Lobry, J.R., Flandrois, J.P., Carret, G., Pave, A., 1992. Monod's bacterial growth model revisited. Bulletin of Mathematical Biology 54, 117-122. https://doi.org/10.1007/BF02458623

Madsen, E.L., Alexander, M., 1982. Transport of Rhizobium and Pseudomonas through Soil. Soil Science Society of America Journal 46, 557-560. https://doi.org/10.2136/sssaj1982.03615995004600030023x

Monod, J., 1949. The growth of bacterial cultures. Annual Review of Microbiology 3, 371394. https://doi.org/10.1146/annurev.mi.03.100149.002103

Nunan, N., Young, I.M., Crawford, J.W., Ritz, K., 2007. Bacterial interactions at the microscale - Linking habitat to function in soil, in: Franklin, R., Mills, A. (Eds.), The Spatial Distribution of Microbes in the Environment. Springer, Dordrecht, pp. 61-85.

Nunan, N., Schmidt, H., Raynaud, X., 2020. The ecology of heterogeneity: soil bacterial communities and C dynamics. Philosophical Transactions of the Royal Society B: Biological Sciences 375, 20190249. https://doi.org/10.1098/rstb.2019.0249

Ohta, H., Taniguchi, S., 1988. Growth characteristics of the soil oligotrophic bacterium: Agromonas oligotrophica JCM 1494 on diluted nutrient broth. The Journal of General and Applied Microbiology 34, 349-353. https://doi.org/10.2323/jgam.34.349

Or, D., Smets, B.F., Wraith, J.M., Dechesne, A., Friedman, S.P., 2007. Physical constraints affecting bacterial habitats and activity in unsaturated porous media - a review. Advances in Water Resources 30, 1505-1527. doi:10.1016/j.advwatres.2006.05.025 
Pagel, H., Kriesche, B., Uksa, M., Poll, C., Kandeler, E., Schmidt, V., Streck, T., 2020. Spatial control of carbon dynamics in soil by microbial decomposer communities. Frontiers in Environmental Science 8, 2. https://doi.org/10.3389/fenvs.2020.00002

Pallud, C., Dechesne, A., Gaudet, J.P., Debouzie, D., Grundmann, G.L., 2004. Modification of spatial distribution of 2,4-dichlorophenoxyacetic acid degrader microhabitats during growth in soil columns. Applied and Environmental Microbiology 70, 2709-2716. https://doi.org/10.1128/AEM.70.5.2709-2716.2004

Patarinska, T., Dochain, D., Agathos, S.N., Ganovski, L., 2000. Modelling of continuous microbial cultivation taking into account the memory effects. Bioprocess Engineering 22, 517-527. https://doi.org/10.1007/s004499900095

Pfeiffer, T., Schuster, S., Bonhoeffer, S., 2001. Cooperation and Competition in the Evolution of ATP-Producing Pathways 292, 5.

Pieper, D.H., Reineke, W., Engesser, K.-H., Knackmuss, H.-J., 1988. Metabolism of 2,4dichlorophenoxyacetic acid, 4-chloro-2-methylphenoxyacetic acid and 2methylphenoxyacetic acid by Alcaligenes eutrophus JMP 134. Archives of Microbiology 150, 95-102. https://doi.org/10.1007/BF00409724

Pinheiro, M., Garnier, P., Beguet, J., Martin Laurent, F., Vieublé Gonod, L., 2015. The millimetre-scale distribution of 2,4-D and its degraders drives the fate of 2,4-D at the soil core scale. Soil Biology and Biochemistry 88, 90-100. https://doi.org/10.1016/j.soilbio.2015.05.008

Pinheiro, M., Pagel, H., Poll, C., Ditterich, F., Garnier, P., Streck, T., Kandeler, E., Vieublé Gonod, L., 2018. Water flow drives small scale biogeography of pesticides and bacterial pesticide degraders - A microcosm study using 2,4-D as a model 
compound. Soil Biology and Biochemistry 127, 137-147.

843 https://doi.org/10.1016/j.soilbio.2018.09.024

844

845

846

847

848

849

850

851

852

853

854

855

856

857

858

859

860

861

862

863

Poll, C., Ingwersen, J., Stemmer, M., Gerzabek, M.H., Kandeler, E., 2006. Mechanisms of solute transport affect small-scale abundance and function of soil microorganisms in the detritusphere. European Journal of Soil Science 57, 583-595. https://doi.org/10.1111/j.1365-2389.2006.00835.x

Portell, X., Pot, V., Garnier, P., Otten, W., Baveye, P.C., 2018. Microscale Heterogeneity of the Spatial Distribution of Organic Matter Can Promote Bacterial Biodiversity in Soils: Insights From Computer Simulations. Frontiers in Microbiology 9, 1583. doi:10.3389/fmicb.2018.01583

Raynaud, X., Nunan, N., 2014. Spatial Ecology of Bacteria at the Microscale in Soil. PLoS ONE 9, e87217. https://doi.org/10.1371/journal.pone.0087217

Roller, B.R., Schmidt, T.M., 2015. The physiology and ecological implications of efficient growth. The ISME Journal 9, 1481-1487. https://doi.org/10.1038/ismej.2014.235

Shampine, L.F., Reichelt, M.W., 1997. The MATLAB ODE Suite. SIAM Journal on Scientific Computing 18, 1-22. https://doi.org/10.1137/S1064827594276424

Sibly, R.M., Hone, J., 2002. Population growth rate and its determinants: an overview. Philosophical Transactions of the Royal Society of London. Series B: Biological Sciences 357, 1153-1170. https://doi.org/10.1098/rstb.2002.1117

Sinton, G.L., Fan, L.T., Erickson, L.E., Lee, S.M., 1986. Biodegradation of 2,4-D and related xenobiotic compounds. Enzyme and Microbial Technology 8, 395-403. https://doi.org/10.1016/0141-0229(86)90145-6 
864

865

866

867

868

869

870

871

872

873

874

875

876

877

878

879

880

881

882

883

884

885

Stana, R.L., 2020. Diffusive transport: theory and application (Doctor of Philosophy thesis). University of Leeds, UK.

Tecon, R., Or, D., 2017. Biophysical processes supporting the diversity of microbial life in soil. FEMS Microbiology Reviews 41, 599-623. https://doi.org/10.1093/femsre/fux039

Tecon, R., Ebrahimi, A., Kleyer, H., Erev Levi, S., Or, D., 2018. Cell-to-cell bacterial interactions promoted by drier conditions on soil surfaces. Proceedings of the National Academy of Sciences 115, 9791-9796. doi:10.1073/pnas.1808274115

Tuxen, N., de Lipthay, J.R., Albrechtsen, H.-J., Aamand, J., Bjerg, P.L., 2002. Effect of exposure history on microbial herbicide degradation in an aerobic aquifer affected by a point source. Environmental Science \& Technology 36, 2205-2212. https://doi.org/10.1021/es0113549

Ugalde-Salas, P., Desmond-Le Quéméner, E., Harmand, J., Rapaport, A., Bouchez, T., 2020. Insights from Microbial Transition State Theory on Monod's Affinity Constant. Scientific Reports 10, 5323. doi:10.1038/s41598-020-62213-6

Vieublé Gonod, L., Chenu, C., Soulas, G., 2003. Spatial variability of 2,4dichlorophenoxyacetic acid $(2,4-D)$ mineralisation potential at a millimetre scale in soil. Soil Biology and Biochemistry 35, 373-382. https://doi.org/10.1016/S00380717(02)00287-0

Young, I.M., Crawford, J.W., Nunan, N., Otten, W., Spiers, A., 2008. Chapter 4 Microbial distribution in soils, in: Advances in Agronomy. Elsevier, pp. 81-121. https://doi.org/10.1016/S0065-2113(08)00604-4 
886 Zelenev, V.V., van Bruggen, A.H.C., Semenov, A.M., 2005. Modeling wave-like dynamics of 887 oligotrophic and copiotrophic bacteria along wheat roots in response to nutrient 888 input from a growing root tip. Ecological Modelling 188, 404-417.

889 https://doi.org/10.1016/j.ecolmodel.2005.01.046 